gen Verbreitung und der kaum noch stattfindenden Verbindung mit politischen Forderungen aus anderen sozialen Bereichen, nicht in einer starken Äquivalenzbeziehung stehen und somit hier vereinfachend als demokratische Forderungen klassifiziert werden ${ }^{55}$. Obwohl vor allem GRÜNE und LINKE immer wieder die „Energiewende"-Politik der Regierungskoalitionen kritisieren ${ }^{56}$, findet eine Artikulation einer grundlegend ,anderen“ „Energiewende“ kaum noch statt, was letztlich zu einer Ausbreitung der hegemonialen Formation führt - eine antagonistische Zweiteilung des diskursiven Raumes ist zumindest auf parlamentarischer Ebene kaum noch erkennbar.

Die hier aufgrund der bisherigen Datenlage interpretierten Trends im Diskurs über „Energiewende“ werden in den folgenden Analyseschritten weiter vertieft und qualitativ bewertet.

\title{
5.2 STORY-LINES IM DISKURS UM „ENERGIEWENDE“
}

Während im vorangehenden Kapitel regelmäßige Differenzbeziehungen von Elementen identifiziert wurden, werden nun komplexere Verknüpfungen in Bedeutungssystemen herausgearbeitet und nach Story-Lines kodiert. Um das genaue methodische Vorgehen in diesem Analyseschritt nachzuvollziehen, verweise ich auf Kapitel 4.2.2, in dem das Verfahren präzise aufgeschlüsselt ist. Auf eine erneute Wiedergabe der Methodik möchte ich daher an dieser Stelle verzichten.

Die im Folgenden beschriebenen Story-Lines reduzieren „Energiewende“ jeweils auf eine bestimmte Weise, sie ,erzählen“ also jeweils einen Teil von „Energiewende“ aus einer spezifischen, komplexitätsreduzierenden Perspektive. Da die Mitglieder des Bundestages als Teil der Konstruktion von „Energiewende“ betrachtet werden, sind die in Bundestagsdebatten identifizierten Story-Lines als grundlegend für die hier getroffenen politischen Entscheidungen anzusehen. Unter Story-Lines werden komplexe Artikulationen verstanden, die auch Verknüpfungen „oberhalb der Wort- und Satzebene“ (Glasze u.a. 2009: 293) beinhalten. D.h. im Gegensatz zum vorigen Kapitel, in dem die Beziehungen zwischen einzelnen spezifischen Elementen betrachtet wurden, können Story-Lines über verschiedene Elemente, sich im Zeitverlauf ändernde Elemente oder sogar über implizite Abgrenzung artikuliert werden. Von einer Story-Line wird gesprochen, wenn ein Teil von „Energiewende“ - ob explizit oder implizit - immer wieder auf ähnliche Weise gedeutet oder eingeordnet wird.

Im vorigen Kapitel 5.1 hat sich gezeigt, dass zwischen der 14. und 16. Legislaturperiode kaum von „Energiewende“ gesprochen wurde. Ich betrachte daher im Folgenden auch, welche - expliziten oder impliziten - Abgrenzungen zu „Energiewen$\mathrm{de}^{\text {“ }}$ in dieser Zeit stattfinden und wie sich diese erklären lassen. Darüber hinaus zeigt

55 Aufgrund der - wenn auch schwachen - Verbindung zu anderen politischen Bereichen, haben diese Forderungen sicherlich auch einen popularen Anteil, werden hier aber als demokratisch bezeichnet, um die Schwäche des kritischen Diskurses hervorzuheben.

56 Wie ich oben bereits verwiesen habe, kommt der Opposition unter GRÜNEN und LINKEN im Gegensatz zur Mehrheitsgruppe, die über 80\% der Mandate verfügt, nur ein geringer Redeanteil zu, was dies Positionen zusätzlich marginalisiert. 
sich, welche Story-Lines aus dieser Zeit für den „Energiewende“-Diskurs nach „Fukushima“" anschlussfähig sind, bzw. wie sich diese nach „Fukushima“ verändern.

Zunächst wird untersucht, wie über den Zeitverlauf direkt auf „Energiewende“ verwiesen wird (oder eben nicht verwiesen wird), also wie „Energiewende“ als ,großes Ganzes“ gedeutet/erzählt wird oder welche politischen Ziele „Energiewende“ direkt ersetzen. Ich bezeichne dies als die ,politische Einordnung' von „Energiewende“, da ausgehend von der politischen Schwerpunktsetzung der jeweiligen Regierungskoalitionen die einschneidensten Prägungen des „Energiewende“-Diskurses über die Legislaturperioden hinweg nachgezeichnet werden. Dieses erste Kapitel 5.2.1 dient einer Übersicht über den Diskursverlauf nach Legislaturperioden, bevor auf Deutungszusammenhänge quer zu diesen eingegangen wird.

Im weiteren Verlauf werden die Story-Lines zwischen der 14. bis 18. Legislaturperiode genauer betrachtet. Die in den Kapitelüberschriften 5.2.2 - 5.2.10 bezeichneten Story-Lines zeichnen sich jeweils durch ihre Dominanz im Datenmaterial aus ${ }^{57}$, sie werden überwiegend von den jeweiligen Regierungskoalitionen artikuliert. Herausfordernde Story-Lines werden eher aus der Opposition heraus artikuliert, machen politische Kämpfe sichtbar. Sie werden im Folgenden im Textverlauf von der Beschreibung der dominanten Story-Line formal durch einen Kasten abgegerenzt.

Insgesamt wird also im folgenden Kapitel nachgezeichnet, wie „Energiewende“ im Bundestag erzählt, bzw. gerade nicht erzählt wird und welche Bedeutungskämpfe stattfinden.

\subsection{1 Übersicht über die Entwicklung der politischen Einordnung von „Energiewende“}

Als Einstieg in die Untersuchung der Story-Lines werden nun wie beschrieben die unmittelbar mit „Energiewende“ in Verbindung stehenden Deutungszusammenhänge analysiert und über die Legislaturperioden herausgearbeitet. Dies dient dazu, sich zunächst einen Überblick über die zeitliche Entwicklung des Diskurses zu verschaffen. Es kann zudem gezeigt werden wie die diskursive Einordnung von energiepolitischen Problemen direkt mit der Konstitution politischer Praktiken zusammenhängt.

\section{4. und 15. Legislaturperiode: Energiepolitik im Rahmen von ökologischer Modernisierung und Atomausstieg}

Eine ökologische Modernisierung ist als eines der zentralen Ziele im Koalitionsvertrag der rot-grünen Regierungskoalition von 1998 festgeschrieben: „ökologische Modernisierung als Chance für Arbeit und Umwelt nutzen“ (Koalitionsvertrag 1998: 1). Unter dem Begriff der ,ökologischen Modernisierung‘ sollen wirtschaftliches Wachstum, technischer Fortschritt und umweltpolitische Ziele vereinbart werden. Sie bildet gewissermaßen den konzeptionellen Rahmen, innerhalb dessen die Energieversorgung in der 14. und 15. Legislaturperiode gestaltet werden soll. Während über den grundsätzlichen Ausbau und die Förderung erneuerbarer Energien Einigkeit herrscht, ist die Umsetzung einer umfassenden „Energiewende“ auch innerhalb der Regie-

57 Die Dominanz im Datenmaterial spiegelt dabei wie in Kapitel 4 erläutert aufgrund der unterschiedlichen Redezeiten meist die Kräfteverhältnisse im Bundestag wider. 
rungskoalition selbst umstritten. Differenzen zwischen SPD und GRÜNEN gibt es dabei vor allem bezüglich der Kohlepolitik: „Fakt ist, dass die SPD zur Kohlepolitik ein Stück weit eine andere Position als wir Grüne vertritt. Das ist doch keine Neuigkeit [...]. Jeder - auch wir - weiß, dass das so ist" (GRÜNE 14.12.2001: 20714). Statt Energiepolitik im Kontext einer „Energiewende“ zu debattieren, wird diese daher meist in den Rahmen einer ökologischen Modernisierung gesetzt, welche das Ausmaß der Umstellung der Energieversorgung zunächst offen lässt - es erfolgt also eine implizite Abgrenzung von „Energiewende“. Im Kontext ökologischer Modernisierung werden im parlamentarischen Diskurs umwelt- und energiepolitische Praktiken mit einer marktorientierten liberalen Arbeitsmarkt- und Wirtschaftspolitik konzeptionell verbunden: „Die Kosten für den Faktor Arbeit werden gesenkt. Im Gegenzug wird der Verbrauch von Energie und Rohstoffen verteuert“ (SPD 25.11.1999: 6740). Über „eine in zeitlich vorgegebenen Schritten kalkulierbare Belastung des Energieverbrauchs“, die Ökosteuer, sollen „die Sozialversicherungsbeiträge auf unter 40 Prozent" gesenkt werden (Koalitionsvertrag 1998: 12). Diese Verteuerung von Energie ist dabei hauptsächlich auf das private Verbraucher*innenverhalten ausgerichtet, während Teile der Industrie befreit werden: „Wegen der noch ausstehenden europäischen Harmonisierung der Energiebesteuerung wird in diesem ersten Schritt die energieintensive Wirtschaft bei Heizöl, Gas und Strom nicht belastet" (Koalitionsvertrag 1998: 12).

Der Atomausstieg, als zentrales energiepolitisches Thema der 14. Legislaturperiode, wird gleichzeitig teilweise als „Einstieg in eine andere Energiepolitik“ (SPD 25.11.1999: 6742) gewertet - wenn auch meist ohne diesen mit einer „Energiewende“ $\mathrm{zu}$ verbinden (vgl. Kapitel 5.1.2): „Die Atomenergie ist heute die größte Investitions- und Innovationsbremse beim Umstieg in eine Einspar- und Solarwirtschaft [...]“ (SPD 25.11.1999: 6742). Als Gründe für die Notwendigkeit eines „Atomausstiegs“ werden darüber hinaus das „Restrisiko“ für einen Unfall, das auch durch technischen Fortschritt nicht ausgeschlossen werden könne, nicht-vorhandene Endlager, die Entstehung „waffenfähigen Materials“, die Endlichkeit der Rohstoffe (Uran) sowie das Scheitern der Kernfusion/Transmutation genannt (SPD 14.12.2001: 20707). Erklärtes Ziel der rot-grünen Bundesregierung ist es, den „Atomausstieg“ im Konsens mit den Energieversorgungsunternehmen und „entschädigungsfrei“ zu regeln (Koalitionsvertrag 1998: 15f.). „Mit dem Dreiklang ,Energiesparen, rationeller Energieeinsatz und erneuerbare Energien“" solle die Energieversorgung nach dem „Atomausstieg“ „,auf neue Füße“ gestellt werden (SPD 14.12.2001: 20709). Es gehe auch darum, die „Energieversorgung nachhaltig [zu] machen“ und Arbeitsplätze zu schaffen (SPD 14.12.2001: 20709). Das EEG wird ebenfalls als Bestandteil einer ökologischen Modernisierungspolitik gesehen, die auch internationale Marktchancen eröffnen soll:

„Ich bin davon überzeugt, dass die gezielte Förderung der Stromerzeugung aus regenerativen Energiequellen angesichts der Chancen, die diese Technologien bieten, eine lohnenswerte Investition in die Zukunft ist, und zwar nicht nur in die Zukunft unseres Landes, sondern auch in die Zukunft internationaler Märkte [...]. Wir halten sie für einen wichtigen Schritt im Rahmen der Modernisierungspolitik der Bundesregierung“(SPD 25.02.2000: 8429). 
Anfangs wird dabei häufig der Begriff „Solarzeitalter“ verwendet: „Dieses Gesetz ist die Geburtsurkunde des Solarzeitalters“(GRÜNE 25.02.2000: 8441).

In der 15. Legislaturperiode wird „Energiepolitik“ weiterhin als einer „der zentralen Faktoren für die ökologische Modernisierung“ gesehen (GRÜNE 09.09.2004: 11252). „Energiewende“ wird nun auch explizit als Unterkapitel ökologischer Modernisierung im Koalitionsvertrag 2002 genannt. Der nachhaltige „Erhalt der natürlichen Lebensgrundlagen“ solle "Gerechtigkeit und Wachstum“ sichern (Koalitionsvertrag 2002: 7). Die „Energiewende“ solle helfen, „Lebensqualität und eine intakte Umwelt auch für unsere Kinder und Enkel zu bewahren“ (Koalitionsvertrag 2002: 10). Allerdings wird „Energiewende“ in den Bundestagsdebatten selbst dann kaum noch aufgegriffen. Ein Kohleausstieg steht zunächst nicht zur Debatte, Kohlekraftwerke sollen zunächst effizienter gemacht werden (vgl. z.B. GRÜNE 28.05.2004: 10237).

Wie schon in der 14. Legislaturperiode solle die ökologische Modernisierung die Ziele „Arbeit und Umwelt“ vereinbar machen, „Öko-Effizienz“ steigern, Kosten reduzieren, die Wettbewerbsfähigkeit verbessern, die Umwelt schützen und durch eine „Effizienzrevolution“ die Produktivität sowie den Export steigern (Koalitionsvertrag 2002: 36ff., GRÜNE 28.05.2004: 10238). Durch die wirtschaftlichen Erfolge habe sich auch das Image der „Umweltschützer“ verbessert - diese seien nun nicht mehr die „Miesmacher, Müsliesser“, sondern „die Wegbereiter zu neuem Optimismus in Wirtschaft und Gesellschaft“ (SPD 09.09.2004: 11256).

\section{Versus „Die beschworene Energiewende [...] findet nicht statt“}

Da die rot-grüne Bundesregierung trotz der verabschiedeten Gesetze zu erneuerbaren Energien und dem Atomausstieg in der 14. und 15. Legislaturperiode kein eigenes Energiekonzept vorlegt, kritisieren CDU/CSU und FDP deren Konzeptlosigkeit (z.B.: FDP 14.12.2001: 20714). Sie halten die Energiepolitik insgesamt nicht für schlüssig: „Für die Zukunftssicherung, die Entwicklung regenerativer Energien fehlt ein Konzept. Die Förderung im Bundeshaushalt insgesamt wird deutlich verringert [...]. Aber dieselbe Bundesregierung setzt zugleich auf Großkraftwerke auf der Basis von Kohle und Erdgas“ (CDU 25.11.1999: 6738). Die CDU/CSU glaubt nicht an eine vollständige Umstellung auf erneuerbare Energien und lehnt eine „Energiewende“ ab: „Der Bundesumweltminister und Teile der SPD setzen auf Energieeinsparung und regenerative Energien. Glauben Sie ernsthaft, daß sich der Energiebedarf allein aus Einsparungen, Solarenergie und Wasserkraft befriedigen läßt?“ (CDU 25.11.1999: 6738). „Das wird nicht in Zukunft, geschweige denn kurzfristig machbar sein“ (CDU 25.11.1999: 6738).

Die Atomenergie werde durch Kohleenergie ersetzt, was einer „Energiewende“ widerspreche: „Die beschworene Energiewende, die heute Mittag gerade wieder eine Rolle gespielt hat, findet nicht statt [...]“ (CDU 27.06.2002: 24770). Auch der Bundeskanzler spreche davon, dass ,es noch lange dauern wird, bis sich die Solarenergie durchsetzt, und dass erst einmal Großkraftwerke auf Steinkohleund Braunkohlebasis gebaut werden müssen“ (CDU 27.06.2002: 24770). Daher seien durch den Atomausstieg die Klimaziele nicht länger haltbar: „Mit dem Ausstieg aus der Kernenergie müssen Sie eine $\mathrm{CO}_{2}$-Reduktion in Höhe von rund 100 Millionen Tonnen ersetzen. Sie glauben, Sie könnten das allein durch eine Ener- 
giewende und eine Effizienzrevolution. Auch hier setzt der Wirtschaftsminister in seinem Bericht ein Fragezeichen [...]“ (CDU 14.12.2001: 20710). „Das geht voll zulasten des Klimaschutzziels“ (FDP 14.12.2001: 20714). „Wenn wir einen erfolgreichen Klimaschutz wollen, dann sind wir auch auf Kernenergie angewiesen“ (CDU 09.09.2004: 11254).

CDU/CSU und FDP lehnen darüber hinaus einen Kohleausstieg ab: „Ich sage in aller Deutlichkeit, dass wir weltweit sowohl Öl als auch Steinkohle und Braunkohle in absehbarer Zeit noch nutzen müssen“ (CDU 28.05.2004: 10236).

Hier deutet sich an, wie sich die Diskursformation, die ich oben (vgl. Kapitel 5.1.3) als hegemoniale Formation klassifiziert habe und deren Position ich vereinfachend als ,herkömmliches Energiesystem mit Förderung erneuerbarer Energien beschrieben habe, durch ihre gemeinschaftliche Abgrenzung von „Energiewende“ konstituiert.

\section{Versus Energiepolitik im Rahmen von ökologischem Umbau}

Die PDS spricht nicht von ökologischer Modernisierung, sondern von ökologischem Umbau, den sie von einer marktorientierten Umwelt- und Wirtschaftspolitik abgrenzt. Sie schlägt für den ökologischen Umbau im Energiebereich Maßnahmen vor: Sie fordert „32 Milliarden DM an ökologisch schädlichen Subventionen - das ist ein Volumen, das $30 \mathrm{mal}$ so groß ist wie der Umweltetat“ abzubauen, z.B. „im Verkehrsbereich und beim Kohlebergbau“, indem die „Kilometerpauschale“ umgewandelt werde. Im Kohlebergbau sollen die „freiwerdenden Mittel in den Strukturwandel der Bergbauregionen fließen“, um „alternative Arbeitsplätze“ zu schaffen (PDS 25.11.1999: 6749). Die „eingesparten Mittel“ sollen „quer über alle Haushalte, beispielsweise für die Altbausanierung, für eine ökologische Verkehrswende, für die Förderung erneuerbarer Energien sowie für die Umweltforschung und internationale Klimaschutzmaßnahmen verwendet“" werden, um eine ökologische Wende zu ermöglichen (PDS 25.11.1999: 6749).

Der Umstieg ins Solarzeitalter sei nur möglich, wenn deutlich mehr Energie eingespart würde, dafür müsse das EEG um entsprechende Maßnahmen ergänzt werden (PDS 25.02.2000: 8436). Allerdings sei ein Senken des Nettoverbrauchs in einer ,ständig wachsenden und nach Strom, Wärme und Sprit lechzenden Wirtschaft durch Energieeinsparungen dauerhaft" (PDS 25.02.2000: 8436) unrealistisch. „Ich denke, hier gibt es technisch-technologische Grenzen. Langfristig ist das Wachstumsmodell, welches auch die rot-grüne Koalition hochhält, eine Sackgasse“ (PDS 25.02.2000: 8436). Zudem müsse beim Energieverbrauch auch vielmehr der Strom-, Wärme- und Verkehrsbereich betrachtet werden, ,insbesondere der Schwer- und Flugverkehr“, was alle „erarbeiteten Reduktionsbestrebungen einreißen wird“" (PDS 25.02.2000: 8436).

In diesem Zusammenhang kritisiert die PDS auch eine Wirtschaftsorientierung der rot-grünen Modernisierungspolitik: „Einer nachhaltigen Energiepolitik steht die Wirtschaftspolitik Ihres Kanzlers und Ihres Wirtschaftsministers im Wege“ (PDS 27.06.2002: 24775). Die Ökosteuer habe keine ökologische Lenkungswirkung und sei sozial ungerecht: „Die Ökosteuer schafft keine zusätzliche Finanzierungsgrundlage für den ökologischen Umbau, weil deren Einnahmen aus den 
Energiesteuern fast vollständig für die Senkung der Lohnnebenkosten verwendet werden“ (PDS 25.11.1999: 6748).

Den Atomkonsens der rot-grünen Regierungskoalition hält die PDS für unzureichend: Das Atomausstiegsgesetz „,regelt im Grunde für 20 und mehr Jahre ein "Weiter so!"“ (PDS 14.12.2001: 20717). Auch die GRÜNEN hätten in ihrem Programm für die Bundestagswahl 1998 noch einen sofortigen Atomausstieg gefordert, da die Technologie , riskant und voller Zynismus gegenüber unseren Kindern und Kindeskindern“" sei (PDS 14.12.2001: 20716). Nun habe sich die Bundesregierung ,einer Energielobby unterworfen [...], die auf der Basis einer zentralistischen Großkraftwerkstruktur ihre Macht abgesichert" habe (PDS 14.12.2001: 20717). In Übereinstimmung mit den Umwelt- und Naturschutzverbänden fordere die PDS daher einen „schnellstmöglichen Ausstieg aus der Atomkraft“ (PDS 14.12.2001: 20717).

Hier wird deutlich, wie die PDS eine populare Äquivalenzkette um ökologischen Umbau aufbaut, indem sie diesen mit weitreichenden Forderungen aus verschiedenen sozialen Bereichen verbindet. Allerdings erfolgt eine Artikulation dieser Forderungen im Zusammenhang mit „Energiewende“ kaum (vgl. Kapitel 5.1.2), sodass diese nicht Teil der popularen Äquivalenzkette wird und somit im hier nachgezeichneten kritischen Diskurs noch kaum eine Rolle spielt.

\section{Legislaturperiode: ,breiter Energiemix“ statt „Energiewende“}

Im Koalitionsvertrag der 16. Legislaturperiode (CDU, CSU, SPD) kommt der Begriff der ,ökologischen Modernisierung ' nicht mehr vor. Stattdessen ist von ,Nachhaltigkeit‘ und ,Nachhaltiger Entwicklung“ die Rede. „CDU, CSU und SPD wollen eine nachhaltige Entwicklung“ (Koalitionsvertrag 2005: 17). Die Motive und genannten Zielsetzungen der im Koalitionsvertrag artikulierten Nachhaltigkeit entsprechen dabei weitgehend denen der ökologischen Modernisierung aus den Verträgen der vorangegangen rot-grünen Regierungskoalition. Eine klare Definition des Nachhaltigkeitsverständnisses oder eine Abgrenzung zur ökologischen Modernisierung findet allerdings nicht statt. Eine ,,ambitionierte Umweltpolitik“ solle „einen zentralen Beitrag zur Modernisierung unserer Gesellschaft" leisten und zum Motor für die Wirtschaft werden (Koalitionsvertrag 2005: 17f.).

„Deutschland und Europa brauchen deshalb einen neuen Aufbruch, der die Ziele erfolgreicher wirtschaftlicher Entwicklung und wirksamen Klima- und Umweltschutzes mit den sozialen Anliegen der Menschen im Sinne eines nachhaltigen Wirtschaftens im 21. Jahrhundert zusammenführt. Der wichtigste Schlüssel dazu ist eine Doppelstrategie zur Steigerung der Energie- und Ressourceneffizienz sowie zum Ausbau erneuerbarer Energien und nachwachsender Rohstoffe“ (Koalitionsvertrag 2005: 65).

Es erfolgt dabei eine implizite Abgrenzung zu „Energiewende“: Es ist nicht mehr von einer „Energiewende“ die Rede (dieser Begriff taucht weder im Koalitionsvertrag noch im späteren Eckpunktepapier der Bundesregierung für ein integriertes Energie- und Klimaprogramm (BMU 2007) auf), sondern von „eine[m] breiten Energiemix“, welcher „der erfolgversprechende Weg zur internationalen Wettbewerbsfähigkeit der deutschen Wirtschaft, zur Verringerung der Belastung von Verbrauchern 
und Unternehmen durch steigende Energie- und Rohstoffpreise und gleichzeitig zum Schutz der Erdatmosphäre und der Umwelt" sei (Koalitionsvertrag 2005: 65). Das Ziel sei eine in diesem Sinne „nachhaltige Energieversorgung“, die „wirtschaftliche[...] Preise“ mit „den Herausforderungen des weltweiten Klimawandels“ vereinbare (BMU 2007: 4).

Über die Gestaltung dieses „breiten Energiemixes“ bestehen zwischen CDU, CSU und SPD vor allem ,hinsichtlich der Nutzung der Kernenergie zur Stromerzeugung unterschiedliche Auffassungen“ (Koalitionsvertrag 2005: 50). So fordert die SPD beispielsweise: „Bestandteil einer modernen Energie- und Klimapolitik ist sicherlich nicht eine Renaissance der Atomenergie“ (SPD 02.07.2009: 25697). CDU und CSU befürworten hingegen weiterhin Atomenergie aus Klimaschutzgründen. Auch hier zeigt sich wieder deutlich, wie die die Einordnung energiepolitischer Probleme direkt mit der Konstitution politischer Praktiken zusammenhängt: Mit der Artikulation eines ,breiten Energiemixes' wird vom Fokus auf erneuerbare Energien abgerückt, hin zu verschiedenen Energieträgern. Die CDU spricht sich „,ür einen breiten Energiemix von den Erneuerbaren über Kohle und Öl bis hin zur Kernenergie aus“ (CDU 06.06.2008: 17734). „Irgendeine Quelle auszuschließen hieße eben, den Dreisatz ,sauber, sicher, sozial' aufzugeben. Das wollen wir nicht“ (CDU 06.06. 2008: 17741).

\section{Versus Vollständige Umstellung und radikale „Energiewende“}

Auch die GRÜNEN sprechen in der 16. Legislaturperiode kaum noch von „Energiewende“ (vgl. Kapitel 5.1.2), weshalb eine grundsätzliche Herausforderung der Artikulation eines ,breiten Energiemixes' kaum gelingt. Sie positionieren sich aber für eine ,vollständige Umstellung der weltweiten Energieversorgung auf erneuerbare Energien“ als „entscheidende Lösung, um das Klima zu schützen“ (GRÜNE 06.06.2008: 17737).

Die LINKE fordert in der 16. Legislaturperiode eine ,radikale Energiewende hin zu erneuerbaren Energien“ (LINKE 02.07.2009: 25694), die auch die sozialen Bedingungen und Auswirkungen in den Blick nehme. Die Arbeitsbedingungen in der Branche der erneuerbaren Energien seien schlecht: „Zwölfstundenschichten und schlechte Bezahlung sind keine guten Voraussetzungen für eine Zukunftsbranche. $\mathrm{Zu}$ Recht fordern die Gewerkschaften bessere Sozialstandards“ (LINKE 06.06.2008: 17736). Darüber hinaus habe eine radikale „Energiewende“ auch friedenspolitisches Potenzial:

„Die Umstellung auf eine nachhaltige Energieversorgung ist eine Überlebensfrage [...]. Wer heute auf erneuerbare Energien setzt und dieses Wissen mit Schwellen- und Entwicklungsländern teilt, wird sich morgen nicht an Kriegen um Öl und Gas beteiligen [...]“ (LINKE 02.07.2009: 25694).

Den mit diesen Artikulationen verbundenen Aufbau einer - wenn auch brüchigen - popularen Äquivalenzkette habe ich in Kapitel 5.1.3 dargestellt, ebenso wie die Marginalisierung des kritischen „Energiewende“-Diskurses, der die hegemoniale Formation herausfordert. 


\section{Legislaturperiode I: Zeitalter erneuerbarer Energien und Kernenergie als Brückentechnologie}

Die Energiepolitik der ersten Hälfte der 17. Legislaturperiode ist zunächst durch die diskursive Verknüpfung von „Kernenergie als Brückentechnologie“, Klimaschutz und Ausbau erneuerbarer Energien innerhalb eines „dynamischen Energiemix“ unter dem Oberziel des „Weges in das Zeitalter erneuerbarer Energien“ gekennzeichnet. Diese Verbindung wird vor allem im gleichzeitig mit der Laufzeitverlängerung verabschiedeten Energiekonzept der schwarz-gelben Regierung hergestellt (17/3049) ${ }^{58}$ und verdeutlicht erneut wie die diskursive Einordung der Energiepolitik unmittelbar politische Praktiken konstituiert. Sowohl im Energiekonzept, als auch im Koalitionsvertrag zwischen CDU, CSU und FDP ist keine Rede von „Energiewende“, wodurch erneut eine implizite Abgrenzung erfolgt. Nachhaltigkeit wird aber erneut als Prinzip genannt: „Das Prinzip der Nachhaltigkeit prägt unsere Politik“ (Koalitionsvertrag 2009: 25). „Wir wollen eine ideologiefreie, technologieoffene und marktorientierte Energiepolitik“ (Koalitionsvertrag 2009: 26; 17/3049: 2). Kohlekraft solle dabei weiterhin eine Rolle spielen, auch wenn der „Ausstieg aus dem subventionierten Steinkohlebergbau“ festgeschrieben sei (Koalitionsvertrag 2009: 28; 17/3049: 10). Der Glaube an technischen Fortschritt spielt für das Energiekonzept eine bedeutende Rolle: So solle Carbon Capture and Storage CCS weiter erforscht werden und zukünftig eine klimaneutrale Braunkohleverstromung ermöglichen (Koalitionsvertrag 2009: 28; 17/3049: 9). In der Fusionsforschung wird das Potenzial für die Erschließung ,eine[r] neue[n] umweltfreundliche[n] und sichere[n] Energiequelle" gesehen (Koalitionsvertrag 2009: 34). Deutschland solle bei ,hohem Wohlstandsniveau eine der energieeffizientesten und umweltschonendsten Volkswirtschaften der Welt werden“ (17/3049: 2). Das Energiekonzept ziele auf einen „Umbau“ der Energieversorgungsstrukturen. „Mit dem Energiekonzept“ beschreibe die Bundesregierung „erstmalig den Weg in das Zeitalter der erneuerbaren Energien“ (17/3049: 2). Die Kernenergie solle eine Brücke ,,auf dem Weg dorthin“ sein (17/3049: 2):

„Ein solcher Prozess benötigt nicht nur Zeit, sondern muss auch wirtschaftlich vernünftig ausgestaltet werden. Um diesen Übergang zu gestalten, brauchen wir noch zeitlich befristet die Kernenergie und werden deshalb die Laufzeiten um durchschnittlich zwölf Jahre verlängern“ (17/3049: 8).

Ohne die Kernenergie seien die Klimaziele und erträgliche Energiepreise nicht zu erreichen (Koalitionsvertrag 2009: 29). „[A]lle Forschungsinstitute im Bereich der Wirtschaft haben dargelegt, dass die Kernenergie“ einen „volkswirtschaftlichen Nutzen“ habe (CDU 28.10.2010: 7168). Durch die Laufzeitverlängerung entstehe daher ein Mehrwert: „Das ist ein Lastwagen voller Geld, der verbrannt wird. Wir wollen diesen Lastwagen voller Geld nicht verbrennen, sondern wir wollen das Geld für den schnelleren Umbau unseres Energieversorgungssystems nutzen“ (CDU 28.10.2010: 7168). Insofern sei das neue Energiekonzept „ein Marshallplan für den Umbau der

58 Die Laufzeitverlängerung wird im Rahmen der Änderung des Atomgesetzes verabschiedet, das am 28.10.2010 in zweiter und dritter Lesung verabschiedet wird. Die erste Lesung findet bereits am 01.10.2010 statt. 
deutschen Energiewirtschaft" (CDU 28.10.2010: 7168). Die schwarz-gelbe Regierungskoalition greift dabei immer wieder Artikulationsmuster der rot-grünen Regierungskoalition (ökologische Modernisierung) auf, ohne diese konkret zu benennen: Das Energiekonzept sei „das größte Modernisierungsprogramm für eine gesamte Volkswirtschaft“ und führe zu einer „Harmonisierung von Volkswirtschaft und Klimaschutz ohne Wohlstandsverluste“" (FDP 28.10.2010: 7201). So wird die Differenz dieser Politik zur rot-grünen Energiepolitik verdeckt:

„Das ist eine Revolution im Prozess. Das ist eine grundlegende Umgestaltung unseres Landes. Wir führen sie durch, weil wir glauben, dass sie dem Klimaschutz dient, und Klimaschutz ist unsere Lebensgrundlage. Wir führen diese Umgestaltung durch, weil wir überzeugt davon sind, dass damit eine technologische Modernisierung, eine Innovation, die Erschließung neuer Märkte und die Entstehung Hunderttausender von Arbeitsplätzen, die Stärkung der Wettbewerbsfähigkeit und Zukunftssicherung einhergehen“(CDU 28.10.2010: 7179).

Es handele sich um „eine grundlegende Umformung unserer Lebensweise“, die ,aber kein Verzichtsprozess“" sein solle, sondern ein Modernisierungsprozess, der die Sicherungen von Marktanteilen mit Technologieführerschaft und der Bewahrung der „Schöpfung“ verbinde (CDU 28.10.2010: 7182); Interessant ist, dass in dieser Debatte zum ersten Mal der Begriff der „Energiewende“ wieder aufgegriffen und in die Energiepolitik der Bundesregierung eingebunden wird: Eine „Energiewende ohne zu überfordern“ (CSU 28.10.2010: 7201).

\section{Versus Laufzeitverlängerung als energiepolitische Katastrophe}

Die Opposition unter SPD, GRÜNEN und LINKEN kritisiert dagegen die Laufzeitverlängerung, sie torpediere den von der Regierungskoalition skizzierten Weg in das Zeitalter erneuerbarer Energien. Die Verlängerung der Laufzeiten der Atomkraftwerke verhindere nicht nur Investitionen in erneuerbare Energien (GRÜNE 28.10.2010: 7340), es gehe auch insgesamt „um die Frage, ob wir die Energiewende hin zu den erneuerbaren Energien fortsetzen oder auf die alten Energiestrukturen setzen wollen“ (SPD 28.10.2010: 7218). ,[F]ür die Umwelt und das Klima“ brauche es „die Atomenergie nicht - weder ihr Geld noch den Strom“ (SPD 28.10.2010: 7173).

Die GRÜNEN argumentieren, schwarz-gelb mache „Lobby- und Klientelpolitik“ und trete „die Rechte von Minderheiten mit Füßen“ (GRÜNE 28.10.2010: 7177). Deutschland habe den „drittältesten Kraftwerkspark“ und nicht „die sichersten Atomkraftwerke der Welt" (GRÜNE 28.10.2010: 7177).

Die LINKE kritisiert, dass die Laufzeitverlängerung „den Kampf zwischen Atomenergie und erneuerbaren Energien“ zum Nachteil erneuerbarer Energien einläute (LINKE 28.10.2010: 7188). Auch der Strom werde nicht billiger, sondern die „Profite sacken die Konzerne ein“ (LINKE 28.10.2010: 7196). Die LINKE habe den „rot-grünen Kompromiss“ zwar stets kritisiert, aber diese Aufkündigung sei nun „eine wirkliche Katastrophe“ (LINKE 28.10.2010: 7175) und zwar nicht nur eine ökologische, sondern auch eine sozial- und arbeitsmarktpolitische, da Unternehmen der erneuerbaren Energien Branche gefährdet seien (LINKE 28.10. 2010: 7176). Die Koalition stelle ,absichtsvoll Unfrieden her“, verursache 
„schwere gesellschaftspolitische Auseinandersetzungen“ (LINKE 28.10.2010: 7175).

Es lässt sich hier ein starker kritischer Diskurs identifizieren, der die Laufzeitverlängerung herausfordert, sich aber zunächst nicht durchsetzen kann. Gleichzeitig wird die Forderung einer „Energiewende“ als positive Alternative mit der Energiepolitik der Regierungsfraktionen kontrastiert: „Mit der Laufzeitverlängerung dreht die Bundesregierung das energiepolitische Rad um zehn Jahre zurück und versucht, die Energiewende mit Atomausstieg und Ausbau der erneuerbaren Energien zu beenden“ (GRÜNE 28.10.2010: 7345).

\section{Legislaturperiode II: „Energiewende“ vor dem Hintergrund einer ,neuen Lage“ nach „Fukushima“}

Wie in Kapitel 5.1 dargestellt, disloziert „Fukushima“ den energiepolitischen Diskurs im Bundestag. Die schwarz-gelbe Regierungskoalition spricht von einer ,neuen Lage $^{6}$, die erst durch „Fukushima“ entstanden sei und aufgrund der nun ein Wechsel in der Energiepolitik notwendig sei:

„Und dennoch: Die Bundesregierung konnte und kann [...] nicht einfach zur Tagesordnung übergehen [...]. Deshalb haben wir im Lichte der Ereignisse in Japan veranlasst, dass alle deutschen Kernkraftwerke noch einmal einer umfassenden Sicherheitsprüfung unterzogen werden im Lichte der neuen Lage! Dazu setzen wir die Verlängerung der Laufzeiten der deutschen Kernkraftwerke aus, [...] indem wir für den Zeitraum eines dreimonatigen Moratoriums alle Kernkraftwerke, die 1980 und früher in Betrieb gegangen sind, vom Netz nehmen“ (Angela Merkel $^{59}$ 17.03.2011: 10884f.).

Das Abschalten der Kernkraftwerke wird nun von Angela Merkel zum ersten Mal im Bundestag direkt mit „Energiewende“ verknüpft:

„Nach dem dreimonatigen Moratorium werden wir über die endgültigen Konsequenzen für den Betrieb der Kernkraftwerke entscheiden [...]. Wir werden deshalb die bewusst ehrgeizig kurz bemessene Zeit des Moratoriums nutzen, um die Energiewende voranzutreiben und, wo immer möglich, zu beschleunigen. Denn wir wollen so schnell wie möglich das Zeitalter der erneuerbaren Energien erreichen - das ist unser Ziel [...]“ (Angela Merkel 17.03.2011: 10887).

Dennoch wird zunächst weiterhin von der Notwendigkeit der Kernenergie als Brückentechnologie gesprochen. Die Artikulationen von CDU, CSU und FDP sind dabei immer wieder von Ambivalenzen durchzogen. So plädiert nun auch die FDP für ein Moratorium: "Wenn sich die Fakten ändern, ändere ich meine Meinung" (FDP 24.03.2011: 11294), beschwört aber gleichzeitig die Gefahr einer Deindustrialisierung herauf: „Eine Deindustrialisierung, die gegen Arbeitsplätze und Wohlstand in

59 Ich zitiere im Folgenden Angela Merkel als Rednerin in den Bundestagsdebatten namentlich und hebe dadurch ihre besondere Stellung innerhalb der dargestellten Diskursentwicklung hervor. 
Deutschland gerichtet ist", sei mit schwarz-gelb nicht zu machen (FDP 24.03.2011: 11286).

Nach dem dreimonatigen Moratorium und dem Bericht der „Ethikkommission Sichere Energieversorgung" erfolgt am 09.06.2011 erneut eine Debatte im Bundestag nach einer Regierungserklärung von Angela Merkel: „Fukushima hat meine Haltung zur Kernenergie verändert“ (Angela Merkel 09.06.2011: 12960). Die Entscheidung in den 60er Jahren „maßgeblich auf Atomenergie zu setzen“ wird als „kollektiver Fehler" bezeichnet (CDU 30.06.2011: 13383), der Ausstieg in Bezug auf die Kraftwerksleistung als ,absolut verkraftbar“ angesehen (CDU 30.06.2011: 13369). Gleichzeitig mit dem Ausstieg aus der Kernenergie bekräftigt Angela Merkel ihre Absicht, die erneuerbaren Energien zur zentralen Säule der Energieversorgung machen zu wollen. Sie spricht mit Verweis auf das Energiekonzept 2010 von einem „tiefgreifenden Umbau unserer Energieversorgung“ (Angela Merkel 09.06.2011: 12961). Der „Ausstieg“ sei ohne einen „Umstieg“ nicht zu haben (Angela Merkel 09.06.2011: 12961). Für den Übergang seien aber fossile Kraftwerke notwendig, die daher schneller gebaut werden müssten (Angela Merkel 09.06.2011: 12962f.). „Im Gegensatz zu früheren Versuchen“ sei es nun gelungen „Ökologie und Ökonomie zu verbinden“ ohne sie ,wie in der Vergangenheit gegeneinander aus[zuspielen]“ (CDU 30.06.2011: 13403). Die ,erhöhten Wachstumszahlen“ machen „den zugegeben riskanten Weg dieser Energiewende“ leistbar (FDP 30.06.2011: 13396). Dass diese politische Einordnung von „Fukushima“ letztlich eine Ausbreitung der hegemonialen Formation ermöglicht, hat sich in Kapitel 5.1 .3 bereits angedeutet, und wird tiefgreifender in Kapitel 5.4 analysiert. Dabei arbeite ich auch heraus mit welchen politischen Praktiken diese Ausbreitung in Verbindung steht.

\section{Versus „Energiewende“ als Irrtumsbereinigung}

Die SPD kritisiert nicht die „,neuen Einsichten“, sondern „,das falsche Pathos“ und die „Unaufrichtigkeit“, mit der die Kanzlerin auftrete: „Es kann doch nicht sein, dass ausgerechnet Sie sich hier als die Erfinderin der Energiewende in Deutschland hinstellen“ (SPD 09.06.2011: 12964). Was die Regierung dem Bundestag vorlege sei kein Gesetz zur „Energiewende“, sondern ein „Irrtumsbereinigungsgesetz“ (SPD 09.06.2011: 12965). „Die Gesellschaft war immer schon weiter als Sie“ (SPD 09.06.2011: 12965). Die SPD spricht vom „Ende des Atomzeitalters“, das durch „Zwei tiefe Überzeugungen“ geprägt gewesen sei: „erstens, dass die Technik nie versagt, und zweitens, dass der Mensch nie versagt, und vor allen Dingen, dass nicht beides zum gleichen Zeitpunkt passiert“ (SPD 17.03.2011: 10890). Dennoch seien die „Risiken der Atomtechnologie“ bereits vor Japan bekannt gewesen (SPD 17.03.2011: 10890). Die SPD erinnert daran, dass die Laufzeitverlängerung „Kernbestandteil des sogenannten Energiekonzepts dieser Bundesregierung war“ (SPD 24.03.2011: 11279). ,[J]etzt auf einmal“" wolle die Regierung „einvernehmlich die Energiezukunft“ gestalten (SPD 24.03.2011: 11279).

Die GRÜNEN erklären, Angela Merkel beende „einen persönlichen Kampf“, den sie „gegen die Energiewende“ geführt habe (GRÜNE 09.06.2011: 12973) und, dass ,[d]ieser Schritt [...] diesen Menschen“ gehöre, die sich seit Jahren für die „Energiewende“ engagieren. Das „Gerede von einer Brückentechnologie“ sei nun widerlegt worden (GRÜNE 30.06.2011: 13380). Sie kritisieren aber auch, 
dass die Zielsetzungen für den Ausbau erneuerbarer Energien mit dem Atomausstieg nicht erhöht werden, dass Onshore-Windenergie und Repowering nicht ausreichend gefördert werden. Das zeige, dass die Bundesregierung „das Wesen der Energiewende immer noch nicht verstanden“ habe, denn dieses setze ,eine andere Struktur unserer Energieversorgung voraus, nämlich flexiblere und dezentralere Struktur“ (GRÜNE 09.06.2011: 12974). Die Menschen „,wollen nicht auf Kosten anderer Generationen leben“, weder durch die Kernenergie noch durch die „Kohleverstromung“" (GRÜNE 30.06.2011: 13381).

Es erfolgt hier also eine kritische Positionierung zur Politik der Regierungskoalition durch SPD und GRÜNE. Dieser kritische Diskurs wird allerdings dadurch geschwächt, dass die von der Regierungskoalition vorgeschlagene „Energiewende“ dennoch insgesamt positiv eingeordnet wird: „Jetzt geht es in Richtung Nachhaltigkeit“" (GRÜNE 30.06.2011: 13381). Die GRÜNEN erklären darauf achten zu wollen, „dass da nicht nur Energiewende draufsteht, sondern auch Energiewende drin ist" (GRÜNE 30.06.2011: 13392).

Die LINKE spricht über „Fukushima“ als „Zivilisationsbruch in der Geschichte des industriell-kapitalistischen Zeitalters“ (LINKE 17.03.2011: 10896). Daher fordert sie neben umfassenden Maßnahmen für einen endgültigen Atomausstieg auch „unverzüglich ein Energiekonzept der Zukunft, das mit unabhängigen Wissenschaftlerinnen und Wissenschaftlern, Umweltverbänden und kommunalen Energieversorgern erarbeitet werden muss, also nicht mehr die Handschrift der Energiekonzerne tragen darf" (LINKE 17.03.2011: 10898). Die LINKE fordert den „Atomausstieg [...] untrennbar mit einer Energiewende“ zu verbinden (LINKE 09.06.2011: 12970). Die Bundesregierung dagegen wolle die Energiewende nur „halbherzig“: „Im Kern gehen Sie auf das zurück, was SPD und Grüne mit der Atomlobby schon ausgehandelt und wir schon immer als halbherzig bezeichnet hatten. Das heißt, das, was Sie jetzt vorlegen, ist eine Korrektur der von Ihnen beschlossenen falschen Gesetze“ (LINKE 09.06.2011: 12969). Der „Atomausstieg“" sei bereits bis 2014 machbar (LINKE 09.06.2011: 12969). Gleichzeitig sei in den neuen Gesetzesentwürfen ,nicht eine einzige zusätzliche Fördermaßnahme“ verankert, sie begrenzen die „Macht der vier Konzerne“ nicht und enthalten keine einzige Maßnahme für eine soziale Gestaltung der Energiewende, eine gerechte Kostenverteilung oder faire Arbeitsbedingungen - die „Energiewende“ müsse daher mit einer sozialen Wende und einer „Kulturwende“ verbunden werden (LINKE 09.06.2011: 12971). „Die Energiewende funktioniert nur sozial, oder sie funktioniert gar nicht“" (LINKE 13.06.2013: 31295).

Die LINKE verbindet hier die Kritik an der Regierungskoalition mit einer Forderung nach einer umfassenderen „Energiewende“ und verbindet diese mit popularen Forderungen, die andere soziale Bereiche mit einbeziehen. Allerdings habe ich in Kapitel 5.1 gezeigt, dass diese von den LINKEN und teilweise auch von den GRÜNEN und der SPD artikulierten kritischen Forderungen, die eine ,andere „Energiewende“ in den Blick holen, schwach ausgeprägt sind. 


\section{Legislaturperiode:}

\section{,Vernünftige“, marktwirtschaftliche „Energiewende“}

In der 18. Legislaturperiode ist der „Energiewende“ im Koalitionsvertrag (2013) von CDU, CSU und SPD ein eigenes Kapitel gewidmet. Es ist das erste Mal seit 2002 und somit insgesamt das zweite Mal in der Geschichte der Bundesrepublik, dass „Energiewende“ in einem Koalitionsvertrag vorkommt. Von den Kernkraftwerksbetreibern werde die „Mitwirkung an der Energiewende“ erwartet, für die Beschäftigten sollen „sozialverträgliche Lösungen“ gefunden werden (Koalitionsvertrag 2013: 43). Gleichzeitig werden aber die „konventionellen Kraftwerke“ zum „Teil des nationalen Energiemixes“ und für „auf absehbare Zeit unverzichtbar“ erklärt (Koalitionsvertrag 2013: 40f.). Artikulationsmuster der ökologischen Modernisierung werden aufgegriffen und mit christlichem Anliegen verbunden:

„Die Energiewende ist ein richtiger und notwendiger Schritt auf dem Weg in eine Industriegesellschaft, die dem Gedanken der Nachhaltigkeit und der Bewahrung der Schöpfung verpflichtet ist. Sie schützt Umwelt und Klima, macht uns unabhängiger von Importen, sichert Arbeitsplätze und Wertschöpfung in Deutschland.“ (Koalitionsvertrag 2013: 36).

Ein zentrales Thema im Zusammenhang mit der „Energiewende“ der 18. Legislaturperiode ist die Novellierung des EEG - zunächst 2014 und dann 2016/2017. Die Novellierung zielt auch auf eine Reformierung der „Energiewende“ insgesamt, die verstärkt mit marktorientierten politischen Praktiken verbunden wird, also marktwirtschaftlicher und ,vernünftiger' organisiert werden solle (,mehr Markt und mehr Wettbewerb“ (CDU 27.06.2014: 3935)). So erklärt ein Abgeordneter der CDU [Michael Fuchs], der zuvor Befürworter der Atomenergie war:

„Heute ist für mich eine Premiere: Ich diskutiere über das EEG, ohne dass mir dabei gleich das Messer in der Tasche aufgeht [...]. Genau genommen habe nicht ich mich verändert, sondern das EEG hat sich verändert, und zwar in einer vernünftigen Weise [...]“ (CDU 27.06. 2014: 3935).

Mit dem EEG 2014 solle ,die Energiewende in Deutschland wieder auf ein festes Fundament" gestellt werden (SPD 27.06.2014: 3932). Gleichzeitig wird mit der Novellierung auch eine Reduktion des Tempos des Ausbaus erneuerbarer Energien im Rahmen der „Energiewende“ diskutiert - die Artikulationen von „Energiewende“ sind verstärkt von Ambivalenzen geprägt. Es reiche nicht, „,möglichst schnell erneuerbare Energien auszubauen", sondern es gehe vor allem um Planbarkeit und Berechenbarkeit (SPD 27.06.2014: 3932). Der Ausbau der erneuerbaren Energien gehe im Vergleich zum Netzausbau zu schnell (CDU 01.06.2016: 16984). Denn es gehe „nicht nur um den Ausbau der erneuerbaren Energien auf Teufel komm raus, sondern auch darum, [...] vernünftige wirtschaftliche Strukturen“ zu erhalten (SPD 01.06. 2016: 16978). Immer wieder ist von einem „Drahtseilakt zwischen Umweltverträglichkeit, Bezahlbarkeit und Versorgungssicherheit“ bei der „Energiewende“ die Rede, wobei man nicht allein auf Umweltverträglichkeit setzen dürfe (SPD 01.06. 2016: 16978). Die „Energiewende“ wird als „Modernisierungs- und Investititionsprojekt[...] mit großer internationaler Ausstrahlung“ konstituiert (SPD 29.07. 2017: 24986). Die CDU spricht vom „größte[n] Technologieprojekt unserer Zeit“ 
(CDU 29.06.2017: 24990). Eine „nüchternere[...]“ Betrachtung der „Energiewende“ gilt dabei als positiv, im Mittelpunkt stehen wirtschaftliche Erwägungen (CDU 29.06.2017: 24992). Es deutet sich an, dass es zu einer Konsolidierung der hegemonialen Formation, die sich in der 17. Legislaturperiode auf den Schlüsselpunkt „Energiewende“ ausgebreitet hat, gekommen ist. Diese Konsolidierung sowie die mit ihr in Verbindung stehenden politischen Praktiken werden in Kapitel 5.4 diskutiert.

\section{Versus Konterrevolution gegen die „Energiewende“}

Die GRÜNEN bewerten die Debatten um das EEG 2014 und 2017 als „eine unverfrorene Konterrevolution der alten, dreckigen Energiewirtschaft und deren Fürsprecher hier im Parlament" (GRÜNE 01.06.2016: 16974). Die Bundesregierung wolle „den Ausbau der erneuerbaren Energien [...] begrenzen, um den Kohledreckschleudern von RWE und Vattenfall einen Bestandsschutz zu geben“ (GRÜNE 01.06.2016: 16974). Durch den ausbleibenden Kohleausstieg komme es zu einem „Stromüberschuss“, Kohle- und Atomkraftwerke „,verstopfen das Netz“ (GRÜNE 01.06.2016: 16974). Die große Koalition sage „die Energiewende von unten wieder ab“ (GRÜNE 01.06.2016: 16974). Damit breche die Bundesregierung ihre Zusagen aus dem Pariser Klimaabkommen (GRÜNE 01.06.2016: 16974).

Auch die LINKE argumentiert, dass das Ausbremsen der „Energiewende“ dazu führe, dass 2020 die Klimaziele verfehlt werden: „Das ist wahrlich keine nachhaltige Politik. Diesen Pfusch können wir uns nicht mehr leisten“ (LINKE 29.06.2017: 24987f.). Die LINKE spricht im Zusammenhang mit dem EEG 2014 von einem „schwarze[n] Freitag für die erneuerbaren Energien“. In Wirklichkeit sei es keine „Reform“, sondern „die Beerdigung des Erneuerbare- EnergienGesetzes“ (LINKE 27.06.2014: 3940). Die Koalition wolle „den Ausbau der Erneuerbaren verzögern, um den Energiekonzernen Luft zu verschaffen, damit die fossil-atomare Energiewirtschaft noch eine Weile länger von ihrer dreckigen Kohleverstromung leben kann“" (LINKE 01.06.2016: 16977).

Hier wird deutlich, dass zwar ein kritischer Diskurs die politischen Praktiken der Regierungskoalition herausfordert, dieser Politik aber nur selten umfassende Forderungen im Zusammenhang mit einer , anderen“ „Energiewende“ entgegengestellt werden (vgl. auch Kapitel 5.1.3).

\subsubsection{Förderung und Ausbau erneuerbarer Energien als gemeinsames Ziel}

Wie in Kapitel 5.1 dargestellt ist die Förderung erneuerbarer Energien ein wichtiges erklärtes Ziel der rot-grünen Bundesregierung der 14. und 15. Legislaturperiode, das aber zunächst meist nicht direkt mit „Energiewende“ verknüpft wird. Als zentrales Moment im Diskurs um erneuerbare Energien ist von Anfang an das EEG mit seinen festen Einspeisevergütungen, die „Planungssicherheit“ gewährleisten sollen (SPD 25.02.2000: 8428), auszumachen. Dies wurde bereits in der computerbasierten Analyse deutlich und wird nun durch das Kodieren der Story-Line ,Förderung und Ausbau erneuerbarer Energien als gemeinsames Ziel' anhand der einschlägigen Dokumente qualitativ nachvollzogen. In der 15. Legislaturperiode solle die dem EEG zu- 
grunde liegende „Förderpolitik“ demnach weiter fortgeführt und „weiterentwickelt“ werden, ein Fokus liege nun auch auf der „Exportinitiative Erneuerbare Energien“ (Koalitionsvertrag 2002: 38). Hinsichtlich des Zieles des Ausbaus erneuerbarer Energien scheint dabei im Bundestag über alle Fraktionsgrenzen hinweg Einigkeit zu bestehen, was - wie in Kapitel 5.1.3 gezeigt - eine wichtige Voraussetzung für die spätere Ausbreitung der hegemonialen Formation darstellt.

„Die Bundesregierung und die sie tragenden Fraktionen haben einen Gesetzentwurf zur Förderung der erneuerbaren Energien vorgelegt, der in der Zielsetzung, den Anteil der erneuerbaren Energien in Deutschland zu verdoppeln, von uns unterstützt wird. In dem Ziel eines Ausbaus der Förderung von Energietechnologien, die einen wesentlichen Beitrag zur Klimapolitik darstellen und eine Brücke in die nächsten Jahrzehnte hinein bauen können, gibt es zwischen uns also im Grunde genommen keine Meinungsverschiedenheit“ (CDU 25.02.2000: 8429).

Auch CSU (z.B.: CSU 25.02.2000: 8439) und FDP stimmen dem Ausbau erneuerbarer Energien prinzipiell zu (z.B.: FDP 25.02.2000: 8433), wobei sie darauf bedacht sind, ihre Differenzen aufzuzeigen. Ein vollständiger Umstieg auf erneuerbare Energien steht im Bundestag allerdings kaum zur Diskussion und wird von CDU, CSU und FDP gar für unmöglich gehalten: „Wie sähe denn die deutsche Energiewirtschaft aus, wenn wir, erstens, auf Kernenergie verzichteten und wenn wir, zweitens, auf Kohle verzichteten? Das kann man doch mit regenerativen Energien gar nicht ausgleichen, erst recht nicht zu wettbewerbsfähigen Preisen“ (CDU 09.09.2004: 11254). Als weitere Differenz innerhalb der hier behandelten Story-Line lehnen CDU, CSU und FDP zudem das Konzept der festen Einspeisevergütungen, wie es im EEG verankert ist, ab und fordern eine Finanzierung über den Haushalt ähnlich der Braunkohle (z.B. FDP 25.02.2000: 8434). Die FDP grenzt sich dabei noch weiter ab und verbindet das Element des Wettbewerbs mit der Idee einer Quotenregelung:

„[...V]erlassen Sie die ausgetretenen Pfade der Subventionspolitik [...] und machen Sie den mutigen Schritt nach vorn zu der Vorgabe eines sich jährlich bis zum Anteil von 50 Prozent steigernden Prozentsatzes regenerativer Energien, die dann aber auch untereinander am Markt konkurrieren müssen“ (FDP 25.02.2000: 8443).

Die Förderung erneuerbarer Energien wird also von Anfang von allen Fraktionen als identitätsstiftendes Moment konstituiert, Differenzen zeigen sich dagegen vor allem in der Art der Förderung und dem Umfang des Ausbaus. Diese Differenzen werden insbesondere in den Debatten um die Ausgestaltung des EEG, in welchem sich der Diskurs über die Förderung der erneuerbaren Energien maßgeblich materialisiert, augenscheinlich.

In der 16. Legislaturperiode bekennen sich dann CDU/CSU gemeinsam mit der SPD im Koalitionsvertrag dazu, „das EEG in seiner Grundstruktur fort[zu]führen“ (Koalitionsvertrag 2005: 51). CDU und CSU grenzen sich nun von der FDP ab und revidieren ihre eigene Position zur festen Einspeisevergütung, die sie nun befürworten:

„In steter Regelmäßigkeit bieten Sie [die FDP] uns ein Quotenmodell als Ersatz für das EEG [...]. Wenn Sie sich damit ernsthaft befassten, könnten Sie im europäischen Vergleich sehen: 
Der Ausbau läuft überall dort besser, wo es ähnliche Modelle wie das unsrige gibt. Vor allem sind die erneuerbaren Energien dort sehr viel günstiger, wo es Einspeisegesetze gibt, als dort, wo es Quoten gibt““(CSU 06.06.2008: 17746).

Höhere Ausbauziele hält die SPD nun in Abgrenzung zu den GRÜNEN für unrealistisch (SPD 06.06.2008: 17743). Die prinzipielle Notwendigkeit der Förderung erneuerbarer Energien bleibt aber Konsens im Bundestag, das EEG nimmt über seine breite Anerkennung zunehmend eine Repräsentationsfunktion für den Diskurs um erneuerbare Energien ein, wird so zu einem zentralen Knotenpunkt und zu einem identitätsstiftenden Moment, zu dem sich die Fraktionen (mit Ausnahme der FDP) überwiegend positiv positionieren. Der Fokus des EEG auf den Strombereich wird dabei eher selten thematisiert, auch wenn ab der 16. Legislaturperiode der Wärmebereich zunehmend im Diskurs vorkommt. Im Eckpunktepapier 2007 heißt es: „Die Erneuerbaren Energien sind im Wärmemarkt der , schlafende Riese““ (BMU 2007: 27). ${ }^{60}$

In der schwarz-gelben Koalition der 17. Legislaturperiode gibt nun auch die FDP ihre kritische Positionierung in Bezug auf das EEG auf. Im Energiekonzept 2010 berufen sich die Regierungsfraktionen positiv auf die Förderpolitik des EEG, durch das die „Rahmenbedingungen“ für die internationale „Vorreiterrolle“ Deutschlands im erneuerbare Energien Bereich gelegt wurden (17/3049: 4), was noch einmal die Rolle des EEG als identitätsstiftendes Moment verdeutlicht. Unter Betonung des gemeinsamen Zieles der Förderung erneuerbarer Energien als „Weg in das Zeitalter erneuerbarer Energien“ (17/3049: 2) soll gleichzeitig die Laufzeitverlängerung der Kernenergie als „Brückentechnologie“ vermittelt werden. Der positive Bezug auf das EEG („Das EEG ist ein richtiges Gesetz“ (CDU 28.10.2010: 7183)) sowie das Versprechen einer weitgehenden Umstellung auf erneuerbare Energien (80\% bis 2050) gleichzeitig mit der Laufzeitverlängerung dient somit auch der Verdeckung gesellschaftlicher und politischer Konflikte über die Kernenergie. Die Betonung des allen Fraktionen gemeinsamen Zieles der Förderung erneuerbarer Energien bereits vor „Fukushima“, schwächt dessen dislozierende Wirkung ab - die Kernenergie sollte ja ohnehin nur „Brückentechnologie“ sein. Über die konsensuale Konstruktion der Förderung und des Ausbaus erneuerbarer Energien werden also verschiedene politische Programmatiken vermittelt, deren Konfliktivität über die Betonung des ,Gemeinsamen' verdeckt wird.

Während die SPD in der 17. Legislaturperiode noch auf diese Konfliktivität verweist (z.B.: ,Ihnen passt das EEG nicht. Ihnen passt der Umstieg auf die Erneuerbaren nicht. Insbesondere die PV ist doch Ihr Hauptangriffsfeld“ (SPD 29.03.2012: 20307)), gibt sie in der großen Koalition der 18. Legislaturperiode ihre kritische Diskursposition auf und nähert sich der CDU/CSU an: Mit dem der Äquivalenzierung von „Ausbaukorridor“ mit „erneuerbaren Energien“ wird eine Beschränkung und damit Verlangsamung des Ausbaus auf bestimmte festgelegte Ziele artikuliert (Koalitionsvertrag 2013: 38). Der „Ausbaukorridor“ solle im EEG festgelegt werden und dafür sorgen, dass „die Kosten im Rahmen bleiben“ (Koalitionsvertrag 2013: 38). Die SPD spricht vom Ende der „Zeit der Technologieförderung“ (SPD 27.04.2014:

60 Das EEWärmeG wird im Bundestag gemeinsam mit der EEG-Novelle am 06.06.2008 debattiert und verabschiedet. 
3932). Die Rolle des EEG für den „Energiewende“-Diskurs wird dadurch abgeschwächt.

\section{Versus Förderung erneuerbarer Energien kein gemeinsames Ziel (mehr)}

Die Opposition stellt spätestens ab der 18. Legislaturperiode den unter der StoryLine ,Förderung erneuerbarer Energien als gemeinsames Ziel` artikulierten Konsens im „Energiewende“-Diskurs deutlich in Frage und zeigt so die Brüche in den Artikulationen der Regierungskoalition auf:

Die GRÜNEN kritisieren eine Verlangsamung des Ausbaus erneuerbarer Energien durch die Politik der großen Koalition: „Sie legen hier eine EEG- Novelle vor, die die Erneuerbaren ausbremst, die Bioenergien abwürgt, die Solarenergie über die Sonnensteuer unwirtschaftlich macht, den Ausbau der Windenergie über

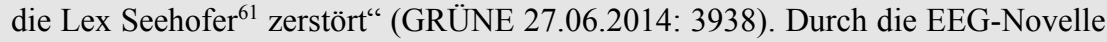
2016 werde der „Ausbau der erneuerbaren Energien um 70 Prozent reduziert“ (GRÜNE 01.06.2016: 16982f.).

Die LINKE kritisiert, durch die Novellierung 2014 werde „der Sinn des EEG in sein Gegenteil verkehrt“, statt erneuerbare Energien zu fördern, würden ,energieintensive Unternehmen subventioniert“ (LINKE 27.06.2014 3934). Die Reform „schaff[e] das EEG eigentlich ab“, es sei ein „Lex RWE“ (LINKE 27.06.2014: 3934).

\subsubsection{Der erneuerbare Energiebereich als Wirtschaftsfaktor}

Wie bereits dargelegt, werden in der 14. und 15. Legislaturperiode erneuerbare Energien vor allem durch die rot-grüne Regierungskoalition diskursiv in eine ökologische Modernisierung eingebettet, die Wirtschaftswachstum, Arbeitsplätze, technischen Fortschritt und Umweltziele vereinbaren solle. Dem erneuerbaren Energiebereich wird darüber hinausgehend eine besondere Bedeutung für die wirtschaftliche Entwicklung zugeschrieben, denn Energie stelle einen „Schlüsselfaktor für die Entwicklung gerade der deutschen Wirtschaft dar“ (SPD 27.06.2002: 24776). Erneuerbare Energien werden dabei nicht nur als Technologie konstituiert, sondern insbesondere auch als Wirtschaftsfaktor, ihnen wird für die Entwicklung der gesamten Volkswirtschaft eine hohe Bedeutung zugeschrieben. Entsprechend werden erneuerbare Energien mit wirtschafts- und technologieorientierten Knotenpunkten äquivalenziert und tragen noch wenig zur Bedeutungsgenerierung von „Energiewende“ bei. Schon bei der Einführung des EEG im Jahr 2000 stehen Exportmöglichkeiten im Fokus: „Die erneuerbaren Energien sind innovative Technologien, die neue Exportmöglichkeiten eröffnen und Arbeitsplätze vor allem im Mittelstand schaffen und sichern [...]“ (SPD 25.02.2000: 8428). Darüber hinaus solle der Gesetzesentwurf bewirken, „dass es in dieser Branche brummt" (GRÜNE 25.02.2000: 8432). Daher begrüße auch die Industrie das Gesetz, z.B. der Verband Deutscher Maschinen- und Anlagenbau VDMA

61 Einführung eines Abstandes von Windenergieanlagen von ca. $2 \mathrm{~km}$ zur Wohnbebauung in Bayern (2014) 
(Europas größter Industrieverband): „Der VDMA hält das Gesetz ebenfalls für hervorragend. Er sagt: Wir entwickeln mit diesem Gesetz eine Exportbranche mit großen Zukunftschancen“ (GRÜNE 25.02.2000: 8433). Zeitlich wird die Verabschiedung des EEG aus diesem Grund vor der Expo 2000 terminiert, die Konstitution des EEG als Wirtschaftsfaktor rechtfertigt dieses Vorgehen: „Es kommt uns darauf an, dieses Gesetz schnell zu verabschieden. Wir wollen es noch vor der Hannover-Messe landen [...]“ (SPD 25.02.2000: 8450). Die FDP bezeichnet das zu diesem Zeitpunkt als „eine knallharte Interessenpolitik“, es gehe der Regierungskoalition „nicht mehr primär um die Umwelt, sondern allein um Klientelpolitik“ (FDP 25.02.2000: 8442).

In der 15. Legislaturperiode festigt sich die Tendenz, den erneuerbaren Energiebereich als für die wirtschaftliche Entwicklung bedeutsam zu konstituieren - es gelingt eine temporäre Fixierung der erneuerbaren Energien als Wirtschaftsfaktor. „Die erneuerbaren Energien bringen Dynamik in den Arbeitsmarkt und steigern die Wettbewerbsfähigkeit“ (GRÜNE 28.05.2004: 10237). In diesem Kontext wird auch der Emissionshandel gesehen, er soll „Investitionen anreizen“ und „zu einer Jobmaschine“ werden (SPD 28.05.2004: 10250). Besonders betont werden zudem die Potentiale im internationalen Wettbewerb. Wegen der „technologische[n] Führerschaft“ Deutschlands setzen internationale Absatzmärkte wie China ,auf Deutschland als Partner“, wegen ihrem ,internationalen Erfolg“ und ihrer „Arbeitsplatzwirksamkeit“ sei die „Exportinitiative für erneuerbare Energien“ daher „außerordentlich vernünftig“ (SPD 09.09.2004: 11256).

\section{Versus rot-grüne Energiepolitik als Gefahr für den Standort Deutschland}

Vor allem die CDU/CSU aber auch die FDP konstruieren in der 14. und 15. Legislaturperiode die rot-grüne Energiepolitik als Gefahr für die wirtschaftliche Entwicklung: „Wie wirkt nun [...] die Energiepolitik dieser Koalition auf die wirtschaftliche Entwicklung? [...] Das, was Sie eingeleitet haben, führt zu einer ganzen Reihe von zusätzlichen Belastungen [...]“" (CDU 14.12.2001: 20710). Anscheinend herrsche auch innerhalb der Regierungskoalition keine Einigkeit über die wirtschaftlichen Auswirkungen des „Atomausstiegs“, eine abweichende Meinung werde bspw. vom Wirtschaftsminister vertreten: „Der Wirtschaftsminister hat zu Recht darauf hingewiesen, dass wir den Stromerzeugungsstandort Bundesrepublik Deutschland durch Ihre Vorgehensweise tendenziell gefährden“ (CDU 14.12.2001: 20711). Der Ausstieg aus der Kernenergie sowie „die Verdrängung heimischer Steinkohle und Braunkohle“ gefährde die Versorgungssicherheit, die Wettbewerbsfähigkeit, Arbeitsplätze sowie den „Produktionsstandort für Strom in der Bundesrepublik Deutschland“ (CDU 14.12.2001: 20711). In diesem Zusammenhang kündigt die CDU an, den „Atomausstieg“ zu revidieren: „Ich sage ganz klar und eindeutig: Herr Trittin, Sie freuen sich zu früh. Wir werden das, was Sie als dauerhaften Kernenergieausstieg bezeichnen, wieder rückgängig machen“ (CDU 14.12.2001: 20711). Durch erneuerbare Energien könne die Energieversorgung nicht sichergestellt werden, weshalb der „Atomausstieg“ die Abhängigkeit vom Ausland erhöhe. Diese gefährde die deutsche Energieversorgung: „Wir werden noch große Probleme bekommen. Lieber deutsche Ingenieure als verrückte Derwische in Nahost als Garanten unserer Energieversorgung!“ (FDP 09.09.2004: 
11229). Hier verdeutlicht sich die von Beginn an ambivalente Haltung in den Fraktionen von CDU, CSU und FDP zu den erneuerbaren Energien, auf die sie sich einerseits positiv beziehen, deren zu starke Ausbreitung sie aber als Gefahr für den Wirtschaftsstandort konstituieren. Diese ambivalente Haltung verdeutlicht nochmals wie die Bedeutung der Forderung ,erneuerbare Energien` zwischen Hegemonie und Gegen-Hegemonie flottiert, wie in Kapitel 5.1.3 deutlich wurde.

In der großen Koalition der 16. Legislaturperiode greifen CDU und CSU dann verstärkt die Artikulation von erneuerbaren Energien als Wirtschaftsfaktor auf und tragen somit wiederum zu einer Verfestigung dieser Story-Line bei. ${ }^{62}$ Erneuerbare Energien werden durch die Betonung ihrer positiven wirtschaftlichen Effekte beinahe mythenhaft aufgeladen. Die SPD spricht von einem „Jobwunder“, von erneuerbaren Energien als „volkswirtschaftliche Lebensversicherung“, von „Gründungswundern“ im Solarbereich, die an die industrielle Revolution erinnern (SPD 06.06.2008: 17730). In der 16. Legislaturperiode kommen zudem die erneuerbaren Energien als Wirtschaftsfaktor für den ländlichen Raum und dabei vor allem die Landwirtschaft/die Agrarindustrie in den Fokus: „Wir haben [...] mit dem EEG im Bereich der Bioenergien ein zusätzliches Standbein für die Landwirtschaft geschaffen" (SPD 06.06.2008: 17739). Die Argumentation der Stärkung der Landwirtschaft wird auch von der CSU aufgegriffen, die sich zum Ziel setzt, die „Konkurrenzfähigkeit der Landwirtschaft gegenüber den großen Playern [...] zu sichern [...]“ (CSU 06.06. 2008: 17747).

Mit der schwarz-gelben Koalition der 17. Legislaturperiode wird die Äquivalenzbeziehung zwischen den erneuerbaren Energien und ihren positiven wirtschaftlichen Effekten weiter gestärkt. Wie bereits die CDU/CSU in der 16. Legislaturperiode artikuliert nun auch die FDP erneuerbare Energien als Wirtschaftsfaktor und bedient somit diese Story-Line. Im Koalitionsvertrag wird der Ausbau der „Technologieführerschaft“ bei den erneuerbaren Energien als Zielsetzung genannt, „[d]ie Potentiale für Innovation, Wachstum und Beschäftigung beim Umbau unseres Energiesystems sind gewaltig“ (Koalitionsvertrag 2009: 27). Die bspw. durch das EEG „erzielte Investitionssicherheit“" habe ein ,massives Wachstum in allen Bereichen der erneuerbaren Energien erzeugt“, die sich dadurch „zu einem Treiber für Innovation und die Modernisierung der Energieinfrastruktur" entwickeln (17/3049: 4). Der positive Bezug auf erneuerbare Energien als Wirtschaftsfaktor durch schwarz-gelb erleichtert die diskursive Einbindung von „Fukushima“ und die Überwindung der dislozierenden Wirkung des Ereignisses. Der Wandel in der Positionierung weg von der Kernenergie als Teil des Wegs ins ,Zeitalters erneuerbarer Energien“ hin zu einer „Energiewende" wird ebenso wie zuvor die Laufzeitverlängerung mit den daraus resultierenden positiven wirtschaftlichen Effekten gerechtfertigt. Nach „Fukushima“ wird so die

62 Obwohl der Atomausstieg gleichzeitig weiterhin als Gefahr für den Standort Deutschland gesehen wird: „Die Russen haben Erdgas und Erdöl. Die Norweger haben Erdgas. Die Schweden haben Wasserkraft. Die Franzosen haben Atomkraft. Und wir Deutsche? Wir haben die Diskussion und in absehbarer Zeit eine veritable Stromlücke“ (CDU 02.07.2009: 25699). 
Story-Line ,erneuerbare Energien als Wirtschaftsfaktor“ auf die „Energiewende“ ausgeweitet und reartikuliert: Die deutsche Federführung werde eines Tages, wenn auch andere Staaten aus den konventionellen Energien aussteigen, „für unsere deutsche Wirtschaft“ „eine Chance sein (FDP 09.06.2011: 12968). Die „Energiewende“ solle ,zum Erfolg“ gemacht werden, „wegen des Klimaschutzes, aber auch wegen der wirtschaftlichen Perspektiven, die dahinterstehen“" (CDU 13.06.2013: 31290). Dass erneuerbare Energien innerhalb der vorliegenden Story-Line bereits vor „Fukushima“ als Wirtschaftsfaktor konstituiert wurden, erleichtert die Einbindung von „Energiewende“ in die hegemoniale Formation nach „Fukushima“.

Andererseits zeigen sich aber auch nach „Fukushima“" weiterhin ambivalente Artikulationen in Bezug auf erneuerbare Energien bzw. „Energiewende“ als Wirtschaftsfaktor. So wird der Positionswechsel zur „Energiewende“ zwar vor dem Hintergrund positiver wirtschaftlicher Effekte gerechtfertigt, es finden aber zunehmend Abgrenzungsprozesse statt. Bspw. gelten erneuerbare Energien als Wirtschaftsfaktor, solange die energieintensive Industrie nicht gefährdet werde: „Wenn Sie die energieintensive Industrie in diesem Land ihrer Basis berauben [...] dann vernichten Sie Arbeitsplätze“ (CDU 30.06.2011: 13383). An dieser Stelle wird deutlich, wie stark sich im Diskurs hegemoniale ökonomische Strukturen, in diesem Fall im Energiesektor, abbilden, bzw. was diskursiv einer politisch zu fördernden Ökonomie zugewiesen wird und was andererseits hiervon abgegrenzt wird. Der Branche der erneuerbaren Energien, insbesondere der Solarbranche, wird dieser Stellenwert nämlich nicht zugestanden. Hier ist es keine Forderung der Regierungsfraktionen, die in die Krise geratene Solarbranche als Wirtschaftsfaktor und in Verbindung mit den in diesem Bereich bestehenden Arbeitsplätzen zu erhalten, im Gegenteil: „Energiepolitik ist Wirtschaftspolitik“ - „Sozial- und Arbeitsmarktpolitik“ sei eben nicht Zweck des EEG: „Die Vergütung für Solaranlagen nach dem EEG kann nicht mit der Zielrichtung beibehalten werden, Arbeitsplätze in der Solarindustrie zu erhalten“ (CSU 13.06. 2013: 31584). „Wer nicht anpassungsfähig ist und wer den Strukturwandel nicht gestaltet, der wird sein Opfer" (CDU 29.03.2012: 20305). Die Forderungen der Opposition, die Branche zu retten, werden als „Besitzstandlobbyismus“ (CDU 29.03.2012: 20305) und „sozialistische [...] Industriepolitik“ bezeichnet (CSU 13.06.2013: 31585). Dabei zeigt sich deutlich, die zumindest teilweise stattfindende Reduktion von „Energiewende“ sowie der erneuerbaren Energien auf ihre Funktion als Wirtschaftsfaktor machen ihren wirtschaftlichen Erfolg gleichzeitig zu ihrer Bedingung:

„So hart das auch klingen mag: In diesen Unternehmen sind wertvolle Arbeitskräfte gebunden: Fachkräfte, die Unternehmen aus anderen Branchen derzeit händeringend suchen [...]. Die gesicherte Existenz der Solarindustrie in Deutschland unter einer Käseglocke aus Staatswirtschaft wird bald ein Ende haben. Die Tage des EEG sind gezählt, egal in welcher Konstellation wir im November hier wieder zusammenkommen“ (FDP 13.06.2013: 31586).

„Energiewende“ als Forderung wird von den Regierungsfraktionen zwar aufrechterhalten, aber gleichzeitig durch ambivalente Artikulationen zunehmend negativ eingebunden.

Unter der großen Koalition der 18. Legislaturperiode verstärken sich die Ambivalenzen der Artikulation von „Energiewende“ und erneuerbare Energien als Wirtschaftsfaktor: Einerseits wird die „Energiewende“ als Chance für die wirtschaftliche 
Entwicklung gesehen, andererseits wird sie aber auch immer wieder als Bedrohung konstruiert und vorherrschenden ökonomischen Strukturen untergeordnet. Ein starkes Motiv der 18. Legislaturperiode ist der Erhalt der Wettbewerbsfähigkeit deutscher Unternehmen und von Deutschland als Industrieland und -standort im Kontext der „Energiewende“. Damit Deutschland „beispielhaft zeigen“ könne, „dass Klimaschutz, Sicherung von Arbeitsplätzen und wirtschaftlicher Erfolg“ vereinbar seien, sei es wichtig ,die energieintensive Industrie vor einer steigenden EEG-Umlage zu schützen“ (SPD 27.06.2014: 3932). Schon heute gehen „die Investitionen in energieintensiven Branchen deutlich zurück“ und schon heute gingen deswegen Arbeitsplätze verloren (SPD 27.06.2014: 3933). Dabei werden Bedrohungsszenarien skizziert: „Wenn wir an der Stelle einen Fehler machen, dann gefährdet das - das muss jeder in diesem Haus wissen - unseren Industriestandort“ (CDU 27.06.2014: 3935). Immer wieder wird die Gefahr einer „Deindustrialisierung“ gezeichnet: „Wir wollen und werden dafür sorgen, dass Deutschland Industrienation bleibt [...]. Diese Koalition und dieser Minister lassen Deindustrialisierung in Deutschland nicht zu“ (SPD 27.06.2014: 3939f.). Dabei zeigt sich erneut eine implizite Abwertung der Branche der erneuerbaren Energien, die als für ihre wirtschaftliche Situation selbst verantwortlich konstituiert wird, gegenüber dem Rest der deutschen Wirtschaft, die „vor unzumutbaren Belastungen“ durch die „Energiewende“ zu schützen sei (SPD 10.04.2014: 2434). Die „Energiewende“ und ihrer Befürworter*innen werden somit immer wieder ins energiepolitische ,Außen“ verwiesen, wobei durch die Regierungskoalition auf ambivalente Weise weiterhin an der Forderung der „Energiewende“ festgehalten wird. Dies gipfelt zum Beispiel im Vorwurf an die GRÜNEN, dass sie an Firmen der erneuerbaren Energien Branche, selbst „massiv beteiligt“ seien und nur deswegen eine Politik zu deren Förderung betrieben. Die Branche der Erneuerbaren sei in Schwierigkeiten geraten, weil „es in dieser Branche unternehmerisches Missmanagement bis zum Gehtnichtmehr" gebe (CDU 01.06.2016: 16975). Die Solarindustrie habe „das süße Gift der Subvention genommen und damit ihre Wettbewerbsfähigkeit gegenüber chinesischen Herstellern verloren“ (CDU 27.06.2014: 3941).

\section{Versus das Ende der Solarindustrie als wirtschaftspolitischer Fehler}

Noch in der 17. Legislaturperiode hatte die SPD kritisiert, der Bundestag beschließe mit der Verabschiedung der EEG-Novelle 2012 „,das Ende der Solarindustrie in Deutschland“, die Koalition verspiele damit „,nicht nur die Energiewende und die Zukunft“, sondern auch deren ,gesellschaftliche Unterstützung“ (SPD 29.03.2012: 20292). In der Regierungsbeteiligung der großen Koalition der 18. Legislaturperiode argumentiert die SPD dann nicht mehr für die Rettung der Solarindustrie. Die GRÜNEN kritisieren daher, der Wirtschaftsminister (Sigmar Gabriel, SPD) kümmere ,sich um jeden Arbeitsplatz in der energieintensiven Industrie, wo die Arbeiter in der IG BCE organisiert sind, persönlich“, habe aber keine „Empathie für Arbeitsplätze in der Branche der erneuerbaren Energien“ (GRÜNE 01.06.2016: 16983).

GRÜNE und LINKE arbeiten die Ambivalenzen in den Artikulationen der Regierungsfraktionen heraus, ihre Positionen bleiben aber - auch aufgrund ihrer ge- 
ringen Redezeiten - marginalisiert. Die Regierungskoalition „treibe[...] diese Branchen mit Ihrer Politik aus dem Land“ (GRÜNE 27.06.2014: 3937). Die Bundesregierung ,zerstöre[...] Zukunftsbranchen“ und vernichte „Zigtausende Arbeitsplätze“, das sei „,wirtschaftspolitisch dumm“ (GRÜNE 01.06.2016: 16975).

Die LINKE bezeichnet die Nicht-Rettung der Solarindustrie als „Politikversagen und einen Skandal“. Der „Zusammenbruch“ führe zu einem „Niedergang ganzer Regionen in Ostdeutschland“ (LINKE 13.06.2013: 31587). Sie verwendet dafür ihrerseits in einem anderen Bedeutungszusammenhang den Knotenpunkt ,Deindustrialisierung‘: Die Regierung sehe ,unbeeindruckt zu, wie eine zweite Deindustrialisierung über den Osten Deutschlands hereinbricht" (LINKE 13.06. 2013: 31587). Das nütze lediglich den „Stromgroßkonzernen“. Dagegen seien die Autoindustrie und die Banken, „die mit halsbrecherischen Spekulationen das Geld ihrer Kunden leichtfertig aufs Spiel gesetzt haben“ mit „großer Selbstverständlichkeit“ „mit Milliarden Steuergeldern“ gerettet worden (LINKE 13.06.2013: 31586). Die LINKE kämpfe „um den Erhalt jedes Arbeitsplatzes“ und für die „Solarindustrie als Standortfaktor“"(LINKE 13.06.2013: 31587).

\subsubsection{Marktorientierung als Bedingung erneuerbarer Energiepolitik und "Energiewende“"}

Mit der Story-Line von erneuerbaren Energien als Wirtschaftsfaktor eng verknüpft ist eine marktorientierte Ausrichtung der Energiepolitik, die ein zentrales Element komplexitätsreduzierender Erzählungen erneuerbarer Energien und später der „Energiewende“ darstellt und daher hier als eigene Story-Line kodiert wird. In der 14. und 15. Legislaturperiode geht es zumeist um die Markteinführung der erneuerbaren Energien als Technologie - eine Verknüpfung zu einer „Energiewende“ bleibt zunächst aus. So wird das EEG als Instrument zur ,Markteinführung', als ,Marktanreizprogramm‘ konstituiert (z.B. GRÜNE 25.02.2000: 8442): „Ziel dieser Maßnahmen muss es sein, die Wirtschaftlichkeit der erneuerbaren Energien zu verbessern, damit sich für diese Technologien langfristig ein sich selbst tragender Markt entwickelt" (SPD 25.02.2000: 8428). Eine zumindest langfristige Marktorientierung der Energiepolitik wird so von Anfang an als Bedingung der Förderung erneuerbarer Energien konstituiert. Dennoch zeigen sich Ambivalenzen in den Artikulationen der rot-grünen Regierungskoalition, denn andererseits wird ein Widerspruch zwischen ,Markt ${ }^{\star}$ und ,Natur' konstruiert:

„Erneuerbare Energien können nicht nach dem traditionellen Bewertungsmuster von Wettbewerb eingeführt werden. [...] Sie können sie nicht gleichschalten, weil man die Natur nicht gleichschalten kann. Wenn man also das Potenzial erneuerbarer Energien nicht ausschließlich nach Marktprinzipien behandeln [...] will, wenn man den Ausbau in der Breite will, dann darf man sich nicht dem neuen Marktgesetz unterwerfen“ (SPD 25.02.2000: 8439).

Dagegen artikulieren CDU, CSU und FDP, die erneuerbaren Energien im EEG als zu „marktfern“ (CSU 25.02.2000: 8440). „Markwirtschaft“ wird mit „Effizienz“, „Kostensenkung“ (FDP 25.02.2000: 8443) sowie „Wettbewerb“ äquivalenziert. 
„Die Finanzierung, Förderung und Markteinführung der erneuerbaren Energien vom Marktgeschehen abzukoppeln ist ein Versagen hinsichtlich der zentralen Herausforderung an die erneuerbaren Energien, nämlich sich dem Wettbewerb zu stellen, ihm langfristig ausgesetzt zu sein, wettbewerbsfähig zu sein, damit wir auch unter dem Gesichtspunkt der Kosten die Energieversorgung in Deutschland sicherstellen können.“ (CDU 25.02.2000: 8430).

In der 15. Legislaturperiode intensiviert sich der Fokus auf eine Marktorientierung des Energiebereichs im Zuge der Debatte um den Emissionshandel. Der Emissionshandel solle als neues „marktwirtschaftliches Instrument“ eingeführt werden, das „am preisgünstigsten“ Emissionen vor allem im Energiebereich einspart (SPD 28.05.2004: 10248) und wird so als marktorientiertes Instrument der Energiepolitik konstituiert. Man wolle „gemeinsam noch mehr auf den Markt setzen“ (SPD 28.05.2004: 10248f.). Neue effiziente Anlagen sollen einen Wettbewerbsvorteil erhalten, weil sie Emissionsrechte ,,am Markt verkaufen“ können, während alte Anlagen Rechte zukaufen müssen (SPD 28.05.2004: 10248f.). Die Äquivalenzierung von Marktorientierung mit Klimaschutz und Energie findet Zustimmung über die Reihen der Regierungskoalition hinweg. Auch die CDU/CSU (z.B. CDU 28.05.2004: 10236) sowie die FDP begrüßen die Einführung von Emissionshandel, denn es gehe „um nicht weniger als die Umstellung in der Umweltpolitik von der bisherigen reinen Ordnungspolitik hin zu einem marktwirtschaftlichen Instrument“ (FDP 28.05.2004: 10239). Allerdings habe die rot-grüne Regierung daraus „ein bürokratisches Monstrum“ gemacht, die Investitionsanreize funktionieren nicht richtig (FDP 28.05.2004: 10239).

In der 16. Legislaturperiode nähern sich CDU, CSU einerseits und SPD andererseits in ihren Artikulationsmustern an. Die Marktorientierung als Bedingung für erneuerbarer Energien und Klimaschutz erlangt dadurch als komplexitätsreduzierende Erzählung noch mehr Gewicht. Der Klimaschutz und die Energiepolitik sollen mit dem Emissionshandel noch „ökonomisch effizienter“ gestaltet werden (Koalitionsvertrag 2005: 66). Im Zuge der Novelle des EEG 2009 sollen mit verringerten Vergütungssätzen (Degression) Marktanreize gesetzt werden, um „die Technologie zu verbessern“. Dies sei notwendig, damit „der Erfindergeist rege bleibt; denn die ausländische Konkurrenz ist längst aus den Startblöcken heraus“ (CDU 06.06.2008: 17742).

Die GRÜNEN kritisieren zwar die Degressionen in der EEG-Novelle als zu hoch, stützen sich dabei aber selbst auf eine marktorientierte Argumentation und artikulieren damit innerhalb der vorliegenden Story-Line: „[E]in schnell wachsender Markt braucht sensible Marktunterstützung und nicht auf Jahre hinweg starr festgelegte, drastische Vergütungssenkungen“"(GRÜNE 06.06.2008: 17738).

Während die LINKE die Demokratisierung des Strommarktes, im Sinne einer demokratischen behördlichen Kontrolle fordert (LINKE 02.07.2009: 25876), lehnen die anderen Fraktionen dies vor dem Hintergrund einer marktorientierten Einbindung der Energiewirtschaft ab: „Die Union hat den Wettbewerb im Blick und wird ihn weiter stärken. Wir sind die Partei der sozialen Marktwirtschaft [...]. CDU und CSU lehnen die sozialistische Lenkung der Energiewirtschaft und andere Formen des Kollektivismus ab.“ (CDU 02.07.2009: 25872). „Monopole, auch staatliche, sind aber der natürliche Feind des Fortschritts und damit auch der dringend erforderlichen Energiewende"(GRÜNE 02.07.2009: 25877). Hier zeigt sich somit die Hegemoniali- 
tät einer marktwirtschaftlichen Ausrichtung der Ökonomie im Diskurs um „Energiewende“.

In der 17. Legislaturperiode intensiviert sich unter schwarz-gelb der Fokus auf eine Marktorientierung als Bedingung erneuerbarer Energiepolitik weiter. Im Jahr 2010 verabschiedeten Energiekonzept geht es zunächst darum, den ,Weg in das Zeitalter erneuerbaren Energien“ marktorientiert zu gestalten: „Wir wollen den Wettbewerb und eine marktwirtschaftliche Orientierung auf den Energiemärkten stärken. Damit sichern wir nachhaltige wirtschaftliche Prosperität, zukunftsfeste Arbeitsplätze, Innovationen und die Modernisierung unseres Landes“ (17/3049: 2). Man setze auf eine „marktorientierte Energiepolitik“, die mit der Kernenergie als „Brückentechnologie“ äquivalenziert wird (17/3049: 2). Auf dem ,Weg in das Zeitalter erneuerbarer Energien“ soll vor allem auf die Initiative privater Unternehmen gesetzt werden: „Das ist die richtige Balance zwischen Markt und Staat. Das ist soziale Marktwirtschaft“ (FDP 28.10.2010: 7173). Auch das EEG solle in Zukunft „stärker am Markt orientiert werden und der weitere Ausbau der erneuerbaren Energien in stärkerem Maße marktgetrieben erfolgen“ (17/3049: 4). Dafür wird das ab diesem Zeitpunkt regelmäßig verwendete diskursive Muster „Schrittweise Markt- und Systemintegration der erneuerbaren Energien“" eingeführt (17/3049: 11). Die Marktintegration wird zunehmend als eine quasi-natürlichen Voraussetzung für die weitere Etablierung erneuerbarer Energien konstituiert. Die Naturalisierung des marktorientierten Ökonomieverständnisses ist dabei als identitätsstiftendes Moment seiner Befürworter*innen zu werten. Dieses prägt den Diskurs zunächst implizit, materialisiert sich dann aber immer wieder in entsprechenden Gesetzgebungen: So müsse das EEG geändert werden, ,,damit die erneuerbaren Energien im Markt ankommen und zukunftsfähig sind“ (CDU 28.10.2010: 7184). Das „Strommarktdesign der Zukunft“ solle ,im Kern marktwirtschaftlich ausgerichtet sein“ (17/3049: 8). SPD, GRÜNE und LINKE sprechen dagegen von einem „Systemkonflikt“ zwischen erneuerbaren Energien und konventionellen Kraftwerken, da durch die konventionellen Grundlastkraftwerke regelmäßig zu viel Strom im Netz sei. Erneuerbare Energien können daher nicht einfach in das bestehende System integriert werden (SPD 28.10.2010: 7207; GRÜNE 28.10.2010: 7192; LINKE 28.10.2010: 7188f.).

Da die Marktorientierung der Energiepolitik als eine zentrale Story-Line durch „Fukushima“ nicht disloziert wird, kann diese nach „Fukushima“ zu einer Grundlage des „Energiewende“-Diskurses werden. Durch eine Marktorientierung könne der Ausbau der erneuerbaren Energien nun „schneller“ als unter rot-grün voranschreiten (FDP 30.06.2011: 13375). Bereits in ihrer Regierungserklärung zum „Atomausstieg“ erklärt Angela Merkel „Kosteneffizienz und zunehmende Marktorientierung“ zur „Leitlinie“ des Umstiegs. „Diesem Ziel dient die Novelle des Erneuerbare-EnergienGesetzes“ (Angela Merkel 09.06.2011: 12962). Die Koalition betont „erstmalig Marktmechanismen [ins EEG] einbringen“ zu wollen (FDP 09.06.2011: 12986). Dazu brauche es „Marktprinzipien“, wie z.B. die „Marktprämie“, die als Knotenpunkte von „Subventionen und Regulierungen“ (FDP 30.06.2011: 13375) abgegrenzt werden. Die erneuerbaren Energien sollen ,,mit marktwirtschaftlichen Mitteln in den Markt“ eingeführt werden, das EEG „,so wirtschaftsfreundlich und industriefreundlich“" werden, ,wie es noch nie war“ (CDU 30.06.2011: 13370). Wie bereits im EEG 2009 soll durch Reduktion der Vergütungen die Wettbewerbsfähigkeit gefördert werden (CDU 29.03.2012: 20306). Mit dem EEG 2012 soll das „Marktintegrations- 
modell gesetzlich veranker[t...]“ werden (CDU 29.03.2012: 20306). Die Opposition dagegen habe den eigentlichen Sinn des EEG, „die Markteinführung“, vergessen (FDP 29.03.2012: 20308).

Die „Markt- und Systemintegration“ ist auch ein zentrales Thema der 18. Legislaturperiode. Das wird bereits im Koalitionsvertrag zwischen CDU/CSU und SPD deutlich: „Das EEG ist ein Instrument zur Markteinführung von erneuerbaren Energien. Sie sollen perspektivisch ohne Förderung am Markt bestehen“ (Koalitionsvertrag 2013: 39f.). Das EEG müsse „mehr Markt beinhalten“ (CDU 01.06.2016: 16984). Die erneuerbaren Energien sollten den Strommarkt bestimmen und könnten daher ,nicht dauerhaft in einem vom Markt abgeschotteten Sondersystem untergebracht werden“ (SPD 27.06.2014: 3932). Daher müsse man jetzt „den Systemwechsel hin zu Ausschreibungen vornehmen [...]. Wir müssen aber auch dafür sorgen, dass wir die Preise für erneuerbare Energien durch Markt und Wettbewerb - und nicht mehr im Deutschen Bundestag - festlegen“ (CDU 01.06.2016: 16984). Damit ließen sich alle Schwierigkeiten, wie „Überrenditen“ oder „die Tatsache, dass Bauern bis zu 40000 Euro pro vermieteter Fläche für Windkrafträder bekommen, usw. “ lösen (CDU 01.06.2016: 16979). Während die Regierungskoalition die erneuerbaren Energien in den Markt integriere, lebe die Opposition ,immer noch in der Welt der Markteintrittsinstrumente“ (CDU 01.06.2016: 16984). Die „Kompetenzen der Energiepolitik“ sollen zukünftig im Wirtschaftsministerium „gebündelt werden“ (SPD 10.04.2014: 2443). Auch hier wird im Kontext von Hegemonie deutlich, aus welchem Ökonomieverständnis heraus die „Energiewende“ maßgeblich mit Bedeutung aufgeladen wird.

\section{Versus Zwangsvermarktung und Gefährdung erneuerbarer Energien durch Marktorientierung}

Die GRÜNEN sprechen dagegen von „Zwangsvermarktung“, die vor allem die kleinen Produzent*innen (z.B. den „Familienvater") treffe, die gar keine Chance haben den „Solarstrom vom Hausdach an der Börse zu vermarkten“ - das wirke wie eine 10-20-prozentige Vergütungssenkung (GRÜNE 29.03.2012: 20203). Privatpersonen können keine Energieversorgungsunternehmen sein (GRÜNE 29.03. 2012: 20303). Die GRÜNEN kritisieren die EEG-Reform 2014 gestalte den Ausbau der erneuerbaren Energien nicht marktwirtschaftlich, sondern würge ihn ab (GRÜNE 10.04.2014: 2441).

Während die GRÜNEN eine Marktorientierung aber nicht grundsätzlich in Frage stellen, lehnt die LINKE eine solche generell ab, auch im Rahmen der Debatte um die EEG-Novelle 2012 (LINKE 29.03.2012: 20278). Sie sieht das EEG grundsätzlich durch eine Marktliberalisierung gefährdet: „Sie selbst zerstören das EEG mit dieser Reform (LINKE 27.06.2014: 3941). Die Regierungskoalition wolle mit der „Direktvermarktung und mit Ausschreibungen die Marktliberalisierung“ und gehe dabei weit über EU-Vorschriften hinaus (LINKE 27.06.2014: 3941).

Die Artikulation kritischer Forderungen in- und außerhalb marktorientierter Deutungsmuster im Kontext von Hegemonie wird in Kapitel 5.4 weiter diskutiert. 


\subsection{5 ( $\mathrm{Zu})$ Hohe Kosten erneuerbarer Energien und „Energiewende“}

Eine weitere Story-Line, die sich bereits im Rahmen der computerbasierten Datenanalyse abgezeichnet hat und sich nun in der qualitativen Auswertung der einschlägigen Dokumente bestätigt, ist die komplexitätsreduzierende Erzählung, die erneuerbare Energien und „Energiewende“ auf ihre vermeintlich hohen Kosten reduziert. In der 14. bis 15. Legislaturperiode spielen diese noch eine untergeordnete Rolle. ${ }^{63}$ Zwar werden in der 16. Legislaturperiode dann die Kosten der Energieversorgung im Kontext einer potenziellen Gefährdung der Wettbewerbsfähigkeit der energieintensiven Wirtschaft diskutiert (z.B. Koalitionsvertrag 2005: 85), andererseits ist die Einschätzung der großen Koalition diesbezüglich auch positiv: „Erneuerbare sind nicht umsonst; aber die Kosten bleiben im Rahmen und sind vorhersehbar[...]" (CDU 06.06.2008: 17735). Aufgrund der wachsenden Nachfrage nach Energie bei gleichzeitiger „Verknappung der fossilen Energieträgern“ komme es zu „dramatischen Preissteigerungen", die durch erneuerbare Energien abgemildert werden könnten (CDU 06.06.2008: 17741). Während die FDP weiterhin für eine marktwirtschaftliche Lösung für mehr Wettbewerb zur Reduktion der Kosten erneuerbarer Energien plädiert (FDP 06.06.2008: 17732), kontrastiert die CDU die Kosten des EEG mit den Folgekosten von Erderwärmung und Ressourcenknappheit:

„Es ist richtig - das adressiere ich insbesondere an die FDP -: Durch die erneuerbaren Energien wird Energie kurzfristig sicherlich nicht billiger. Wenn man aber über den Tellerrand hinausschaut, dann stellt man sehr schnell fest, dass wir, wenn wir jetzt nicht handeln, dieses Nichthandeln später teuer bezahlen müssen“ (CDU 06.06.2008: 17741).

Auch die SPD argumentiert, dass „die Beibehaltung der jetzigen Energiepolitik“ durch die Folgekosten des Klimawandels viel teurer sei als die Umstellung auf erneuerbare Energien (SPD 06.06.2008: 17744). Im Gegensatz dazu seien „für die Zukunft unserer Kinder und Enkelkinder 3 oder 5 Euro im Monat verdammt preiswert" (SPD 06.06.2008: 17744). „Zudem werden durch erneuerbare Energien „mindestens 400.000 Arbeitsplätze geschaffen“: „Es ist teurer, wenn diese Leute zum Arbeitsamt geschickt werden“" (SPD 06.06.2008: 17744).

Erst in der 17. und 18. Legislaturperiode werden erneuerbare Energien und „Energiewende“ zunehmend im Kontext von hohen Kosten artikuliert. Auch die Zusammenhänge der diskursiven Elemente verschieben sich: Wurden noch in der vorigen Legislaturperiode die Kosten des Ausbaus erneuerbarer Energien den Folgekosten des Klimawandels gegenüber gestellt, so werden die Kosten erneuerbarer Energien nun verstärkt isoliert artikuliert. So heißt es im Energiekonzept von schwarzgelb unter der Überschrift „kosteneffizienter Ausbau der Erneuerbaren“: „Ziel der Bundesregierung ist es, den Ausbau der erneuerbaren Energien weiter voranzutreiben und zugleich den Druck auf Innovationen und Kostensenkungen weiter zu verstär-

63 Debatten über die Kosten der Energieversorgung zwischen der 14. und 15. Legislaturperiode beziehen sich meist auf die Ökosteuer (z.B.: GRÜNE 09.09.2004: 11253). 
ken“ (17/3049: 4). Kostensenkungsbedarf wird dabei vor allem bei der Photovoltaik gesehen (17/3049: 4).

Nach „Fukushima“ gewinnen Äquivalenzierung der Knotenpunkte ,Kosten“ und ,erneuerbare Energien` weiter an Bedeutung, wobei die Kosten erneuerbarer Energien in den Debatten zunehmend mit den Kosten der „Energiewende“ gleichgesetzt werden. Bereits in der Regierungserklärung zum Atomausstieg, hat das Thema einen hohen Stellenwert. Dabei steht „vor allem die energieintensive Industrie“ und deren Belastung durch die Strompreise im Mittelpunkt (Angela Merkel 09.06.2011: 12962). „Die EEG-Umlage soll nicht über ihre heutige Größenordnung hinaus steigen“, langfristig sollen die Kosten gesenkt werden (Angela Merkel 09.06.2011: 12962). Auch für die FDP hat die „Bezahlbarkeit“ einen hohen Stellenwert, was sie von der Opposition unterscheide (FDP 09.06.2011: 12968; 29.03.2012: 20308). Gleichzeitig stellt die Betonung von Kostensenkungen ein einendes Moment zwischen Befürworter*innen und Gegner*innen erneuerbarer Energien innerhalb der eigenen Fraktion her. Mit den Kosten verbunden wird das Bedrohungsszenario des möglichen Verlusts von „Hunderttausende[n] von Arbeitsplätzen“ in der energieintensiven Industrie (CSU 09.06.2011: 12973; CDU 29.03.2012: 20282).

\section{Versus Befreiung der energieintensiven Industrie als Ursache für hohe Kosten und soziale Ungerechtigkeit}

GRÜNE, LINKE und SPD betonen dagegen, dass die Strompreise ,nicht wegen der Energiewende gestiegen“ seien, sondern ,trotz der Energiewende“ (SPD 29.03.2012: 20283) und verweisen damit auf Brüche in den Artikulationen der Regierungsfraktionen. Die Kosten der Atomenergie seien im Gegensatz zur „Energiewende“ kaum bezifferbar (GRÜNE 30.06.2011: 13381). Durch eine übermäßige Entlastung der energieintensiven Industrie komme es zu einer Umverteilung zwischen Privatverbraucher*innen und großen Unternehmen, die Kosten würden „auf immer weniger Schultern verteilt“ (SPD 29.03.2012: 20282): „Die Mehrkosten tragen die Privathaushalte und die kleinen Unternehmen: also der Rentner für das befreite Hotel, die Krankenschwester für das befreite Rechenzentrum, der Einkaufsmarkt um die Ecke für den Riesenmarkt auf der grünen Wiese und der Handwerker für die Fabrik“" (SPD 29.03.2012: 20283). Auch die GRÜNEN sprechen von einer Umverteilung von ,privaten kleinen Verbrauchern“ „,in Richtung Industrie“, die insgesamt „9 Milliarden Euro“ betrage (GRÜNE 29.03.2012). SPD und GRÜNE fordern zwar eine begrenzte Befreiung der energieintensiven Industrie: „Die energieintensive Industrie gehört zu Deutschland“, weshalb „diese Unternehmen im Land“ gehalten werden müssen (GRÜNE 29.03.2012: 20286). Es sei aber völlig intransparent ,wer genau welche Subventionen bekommt", über die Befreiung von der EEG-Umlage werde der Braunkohletagebau mit 40 Millionen Euro im Jahr subventioniert (GRÜNE 29.03.2012: 20286). Die GRÜNEN kritisieren, dass die ständige Betonung der Kosten der „Energiewende“ bei gleichzeitiger Nichtbetrachtung der Kosten des Klimawandels, diese subvertiere: „In den letzten zwei Jahren wird nur noch gegen die angeblich hohen Kosten der Energiewende gehetzt“, die aber „,keine Kosten, sondern Investitionen gegen den Klimawandel“ seien (GRÜNE 13.06.2013: 31588). Die LINKE betont, dass die Industrie diese strompreissenkenden Effekte für eine 
„Gewinnmacherei im Schatten der erneuerbaren Energien“ nutze, weshalb eine staatliche Preisaufsicht notwendig sei (LINKE 24.03.2011: 11308). So seien die Strompreise an der Börse um 2 Cent gesunken, während die EEG-Umlage nur um 1,5 Cent gestiegen sei - statt Preissenkungen habe es aber Preiserhöhungen gegeben (LINKE 24.03.2011: 11308) - „Das heißt, das Ganze ist eine Gelddruckmaschine“ (LINKE 30.06.2011: 13390) oder auch eine ,gigantische Umverteilungsmaschine“ (LINKE 29.03.2012: 20277), wie es in einer späteren Debatte heißt.

Während die SPD in der 17. Legislaturperiode die umfassenden Befreiungen der energieintensiven Industrie sowie die starke Betonung der Kosten durch schwarzgelb kritisiert, wechselt sie in der 18. Legislaturperiode ihre Diskursposition und wirkt affirmativ auf die Story-Line, die die „Energiewende“ auf ihre Kosten reduziert. Auch durch die starke Positionierung der Mehrheitsgruppe (80\%) im Bundestag kommt den Kosten dadurch ein noch höherer Stellenwert zu. Im Koalitionsvertrag ist von einem „energiepolitischen Dreieck[...]“ aus „Klima- und Umweltverträglichkeit, Versorgungssicherheit [und] Bezahlbarkeit" die Rede (Koalitionsvertrag 2013: 9). Diese Ziele seien gleichrangig. Der „Kosteneffizienz“ soll eine „höhere Bedeutung“ als bisher beigemessen werden (Koalitionsvertrag 2013: 36). Immer wieder ist von einem „Kostenanstieg“ die Rede, dessen „Ausmaß und Geschwindigkeit“ spürbar gebremst werden solle (Koalitionsvertrag 2013: 38f.). Gerade für die Rechtfertigung der Novellierungen des EEG 2014 und 2016/2017 spielt solche Artikulationsmuster eine Rolle: „Es gab beim EEG in wenigen Jahren Kostensteigerungen von mehr als 10 Milliarden Euro“ (SPD 27.06.2014: 3932). Durch die wiederkehrende Äquivalenzierung des Knotenpunktes ,Belastung“ mit „Energiewende“ entsteht der Eindruck, diese sei ,zu teuer‘. So sei die EEG-Umlage ,inzwischen zu einer massiven Belastung geworden“ (SPD 10.04.2014: 2435), „,niemand wird leugnen, dass wir hier auf der Kostenseite ein Problem haben“ (CDU 01.06.2016 16979). Die Ausgaben für erneuerbare Energien in Höhe von 24 Milliarden Euro im Jahr 2014 seien ,eine gewaltige Belastung für uns als Volkswirtschaft, für die Unternehmen, aber auch für die Familien“ (CDU 10.04.2014: 2439). Der Fokus auf Kosten wird diskursiv mit einem Bedrohungsszenario des Verlustes von Wirtschaftskraft verbunden: „Wir müssen die Frage der Energiekosten permanent adressieren [...]; Denn ansonsten werden große energieintensive Unternehmen Deutschland verlassen“ (CDU 10.04.2014: 2439). Die Energiekosten „,bestimmen die Wettbewerbsfähigkeit dieses Landes“ weshalb die Industrie zum Erhalt von Arbeitsplätzen entlastet werden müsse (SPD 10.04.2014: 2434). Die Äquivalenzbeziehung zwischen ,Kosten“ und „Energiewende“ erscheint zunehmend quasi-natürlich, weshalb die Artikulation dieser Verbindung zur Norm wird: „Frau Verlinden [GRÜNE], Sie haben das Wort ,Kosten“ - wir alle können das nachlesen - in Ihrer Rede nicht einmal verwandt“ (SPD 01.06.2016 16989).

\section{Versus die Kostendebatte diskreditiert die „Energiewende“ zu Unrecht}

Wie bereits in der 17. Legislaturperiode bestreiten GRÜNE und LINKE einen allein durch die „Energiewende“ verursachten Kostenanstieg, kritisieren mangelnde Kostengerechtigkeit und heben die Folgekosten von Umweltschäden hervor. Da- 
durch verweisen sie weiterhin auf die Brüche und Widersprüche in den Artikulationen der Regierungsfraktionen, ihre Wirkung auf den Diskurs bleibt aufgrund ihrer geringen Redezeit aber marginal. So argumentieren die GRÜNEN, es gebe „keine explodierende EEG-Umlage“, das sei eine „freie Propagandaerfindung“ (GRÜNE 01.06.2016: 16983). Auch die LINKEN kritisieren die ,unsägliche Kostendebatte“ (LINKE 01.06.2016: 16977). Es mache keinen Sinn die „Energiewende“ gegen ihre Kosten auszuspielen: „Ja, die Energiewende kostet Geld. Keine Energiewende ist um ein Vielfaches teurer“ (LINKE 01.06.2016: 16985). Mit dem Kostenargument werde ausgeblendet, dass „die Alternative viel teurer“ sei „und noch ganz andere Konsequenzen nach sich zieht“ (GRÜNE 01.06.2016: 16983). Zudem sei zwar die EEG-Umlage gestiegen, gleichzeitig sei aber der Börsenstrompreis durch die strompreissenkenden Effekte der erneuerbaren Energien deutlich gesunken (von 10 Cent je Kilowattstunde im Jahr 2008 auf 2,5 Cent je Kilowattstunde im Jahr 2016). Davon profitieren die Bürger*innen und Netzkunden durch die EEG-Umlage nicht, während die Preise für die energieintensiven Unternehmen, die von ihr befreit sind, deutlich gesunken seien: „Es ist eine Umverteilung von den Kleinen zu den Großen, die hier stattfindet“ (LINKE 01.06.2016: 16986). Es könne nicht sein, „dass die privaten Verbraucher zahlen und am Ende nur die Industrie profitiert. Das hat nichts mit Kostengerechtigkeit zu tun“ (GRÜNE 10.04.2014: 2441).

\subsubsection{Deutschland als Vorreiter und „Energiewende“ als nationales Gemeinschaftswerk}

Die bundespolitische Förderung erneuerbarer Energien wird von Anfang an mit dem diskursiven Muster der ,besonderen Rolle' Deutschlands als internationalem Vorbild verknüpft. Dies hat sich bereits im Rahmen der quantitativen Erhebung mit dem durchweg hohen Ranking von „Deutschland“ als häufige Kollokation abgezeichnet und bestätigt sich nun auch in der qualitativen Kodierung der wichtigsten StoryLines: „Ich bin mir ganz sicher, dass viele internationale Augen auf dieses Gesetz schauen werden und viele Erwartungen und Hoffnungen damit verbunden sind“ (SPD 25.02.2000: 8437). Die rot-grüne Regierungskoalition der 14. und 15. Legislaturperiode weist Deutschland im Klimaschutz eine Sonderrolle zu: „Wir setzen damit auch deswegen ein weltweites Signal, weil wir auf diese Weise die Frage des weltweiten Klima- und Umweltschutzes anders angehen, als es bisher bei den Weltklimakonferenzen leider der Fall war“" (SPD 25.02.2000: 8437). Die Förderung erneuerbarer Energien in Deutschland wird dabei auch direkt mit Entwicklungszusammenarbeit verknüpft, denn Deutschland als „Exportland“ trage Verantwortung: „Um sie aber dort [,,in der Dritten Welt"] wirksam werden zu lassen, müssen wir sie hier industriell mobilisieren, und zwar auch mithilfe dieses Gesetzes [...]" (SPD 25.02.2000: 8438). Die Äquivalenzierung der Förderpolitik mit Entwicklungszusammenarbeit sowie der Exportförderung findet auch Zustimmung bei CDU,CSU und FDP, da sie aus marktwirtschaftlicher Perspektive attraktiv erscheint - Deutschland solle die Technologie ,dort einsetzen, wo sie viel mehr und viel effizienter zum Klimaschutz beitragen kann [...]“" (CSU 25.02.2000: 8440). Die FDP möchte daher „,in Entwicklungs- und Schwellenländern [...] investieren, weil dort eine Reduktion 
der Emissionen von $\mathrm{CO}_{2}$ zu deutlich geringeren Kosten möglich ist“ und so „Technologietransfer" und „Exportoffensive“ verbunden werden können (FDP 28.05.2004: 10238). Durch diese Verknüpfung von erneuerbaren Energien mit Forderungen nationaler Interessenpolitik finden somit - wie soeben exemplarisch belegt - von Anfang an auch neokoloniale Elemente Einzug in den „Energiewende“-Diskurs. Was für mich im Rahmen des Forschungsdesigns Anlass war, postkoloniale Perspektiven in die Theoriebildung mit einzubinden (vgl. Kapitel 3.2.2).

Im Zusammenhang mit der von Bundeskanzler Gerhard Schröder einberufenen internationalen Konferenz „renewables2004“ verstärkt sich die Bedeutungsgenerierung erneuerbarer Energien über eine ,besondere Rolle‘ Deutschlands in der Welt im Laufe der 15. Legislaturperiode. Auffällig ist dabei, dass vor allem im Kontext der Thematisierung der internationalen Rolle Deutschlands nun häufiger der Begriff „Energiewende“ verwendet wird, während er in anderen Debatten kaum explizit auftaucht, wie in Kapitel 5.1.2 gezeigt wurde. Demnach spielt „die Konstruktion der Story-Line einer positiv belegten deutschen ,Vorreiterrolle‘ für die Bedeutungsgenerierung von „Energiewende“ von Anfang an eine besondere Rolle. Die Konferenz „renewables2004“ wird direkt mit einer Stärkung dieser Vorreiterrolle verbunden. So würden die 1000 Delegierten ,,aus über 100 Staaten nach Bonn kommen, um diese in Deutschland vollzogene Energiewende zu besichtigen“ (GRÜNE 28.05.2004: 10237). Bereits zuvor habe „eine Parlamentarierdelegation der pazifischen Inselstaaten“ bei einem Besuch in Berlin „die dringende Bitte gerade an uns Deutsche“ gerichtet, „beim Klimaschutz nicht nachzulassen. Wir seien eines der wenigen positiven Beispiele in der Welt“ (SPD 28.05.2004: 10247). „Wir sollten stolz darauf sein, hierzu eine avantgardistische Position einnehmen zu können“ (SPD 28.05.2004: 10241). Mit der deutschen Vorbildfunktion steht der Anspruch der Globalisierung der „Energiewende“ in direkter Verbindung. Die „Energiewende [könne] aber nur nachhaltig sein, wenn sie global ist“" (SPD 28.05.2004: 10234). Der Fokus liegt dabei auf den sogenannten Entwicklungsländern als Handlungsfelder:

„Entwicklungsländer dürfen und wollen nicht die Fehler wiederholen, die die Industrieländer bisher bei ihrer Energieversorgung gemacht haben, denn das hält unser Globus nicht aus [...]. Es gibt also keine Alternativen zu erneuerbaren Energien und zur Steigerung ihrer Effizienz. Außerdem bringt der Einsatz erneuerbarer Energien riesige Vorteile für Entwicklungsländer mit sich“ (SPD 28.05.2004: 10234).

Der erneuerbare Energiebereich biete einen Ansatzpunkt, um den „Zusammenhang zwischen globalen Entwicklungsproblemen und globalen Umweltproblemen“ anzugehen (SPD 28.05.2004: 10241). Deshalb wolle die Bundesregierung vermehrt in erneuerbare Energien in (sogenannten) Entwicklungsländern investieren (GRÜNE 28.05.2004: 10238).

In der großen Koalition der 16. Legislaturperiode etabliert sich die komplexitätsreduzierende Erzählung einer deutschen Vorreiterrolle im Zusammenhang mit Klimaschutz und erneuerbaren Energien weiter: „Deutschland wird weiterhin seine führende Rolle im Klimaschutz wahrnehmen“ (Koalitionsvertrag 2005: 65). Artikuliert wird dabei neben einer Vorbildfunktion auch die wirtschaftliche Position Deutschlands im internationalen Kontext: „Deutschland ist Weltmeister beim Ausbau der erneuerbaren Energien“ (SPD 06.06.2008: 17330); „Das deutsche EEG gilt in der Welt 
als Modell und Vorbild dafür, wie man erneuerbare Energien im Strombereich fördern kann“ (CDU 06.06.2008: 17742). Die CDU betont, „,dass es auf der Welt kein Industrieland gibt, das eine derartig positive energiepolitische Bilanz hat wie wir in Deutschland. Darauf können wir in der Großen Koalition stolz sein“ (CDU 02.07. 2009: 25690). Es wird eine deutsche Technologieführerschaft im Bereich erneuerbarer Energien konstruiert, aus der sich der Anspruch ableitet, diese insbesondere in sogenannten Entwicklungs- und Schwellenländern zu verbreiten: „Mit den Exportinitiativen ,Erneuerbare Energien “ und ,Energieeffizienz' unterstützt die Bundesregierung gezielt deutsche Unternehmen und die weltweite Verbreitung deutscher Spitzentechnologie, gerade auch in Entwicklungs- und Schwellenländern“ (CDU 02.07. 2009: 25690). Die Legitimität der Verbindung wirtschaftlicher Interessen mit Entwicklungszusammenarbeit wird dabei als quasi-natürlich vorausgesetzt: „Energieaußenpolitik ist vor allem auch Entwicklungspolitik“ und „Energieaußenpolitik [ist] insbesondere auch Wirtschaftsförderung und Wirtschaftspolitik" (CDU 02.07.2009: 25697). Dennoch sei Entwicklungspolitik nicht „Mittel zum Zweck“ (SPD 02.07. 2009: 25697). Um die positive Rolle Deutschlands für die Entwicklungszusammenarbeit im Bereich der erneuerbaren Energien hervorzuheben, wird immer wieder auf hohe Summen verwiesen, die investiert werden: „In dem vorgesehenen Zeitraum von 2003 bis 2007 wurden in der bilateralen Zusammenarbeit insgesamt 1,3 Milliarden Euro für erneuerbare Energien zugesagt. Ich finde, das kann sich sehen lassen (SPD 02.07.2009: 25698). ${ }^{64}$

Die komplexitätsreduzierende Erzählung einer ,deutschen Vorreiterrolle' bei den erneuerbaren Energien wird auch in der 16. Legislaturperiode von einer breiten Mehrheit im Bundestag artikuliert. Erneut wird die deutsche Technologieentwicklung mit einer Aufwertung der deutschen Rolle im internationalen Kontext äquivalenziert: „Die ganze Welt schaut staunend auf Deutschland, wo sich in kürzester Zeit eine [...] industrielle Entwicklung für Solarzellen, Windkraft und Biogas entwickelt hat“ (GRÜNE 06.06.2008: 17737). Die FDP möchte „,den Weg für deutsche Firmen in ausländische Märkte politisch [...] begleiten“ (FDP 02.07.2009: 25692). Eine Rolle für eine solche Begleitung spielt dabei das Projekt ,Desertec ${ }^{65 ،}$, auf das sich sämtliche Fraktionen im Deutschen Bundestag positiv beziehen und das - neben seiner Funktion für die Entwicklungszusammenarbeit - mit einer „Sicherstellung des Wohlstandes“ in Deutschland äquivalenziert wird (FDP 02.07.2009: 25692).

\section{Versus ungerechte Ressourcenverteilung und interessengeleitete Politik}

LINKE und GRÜNE fordern die Story-Line einer deutschen Vorreiterrolle im Energiebereich kritisch heraus, indem sie auf eine global ungerechte Ressourcenverteilung hinweisen sowie eine von wirtschaftlichen Interessen geleitete Politik kritisieren und somit die Brüche im Diskurs hervorheben.

64 Dabei wird aber nicht erwähnt, dass es sich überwiegend um Kredite handelt.

65 Unter dem Namen DESERTEC wird die Vision verfolgt überwiegend Solarstrom in den Wüstenregionen Nordafrikas zu produzieren und von dort in die Verbrauchszentren, auch nach Europa, zu übertragen (www.desertec.org). 
Vor dem Hintergrund einer gerechteren Ressourcenverteilung müsse Deutschland seinen Energieverbrauch einschränken, um den weltweiten Nachfragedruck zu mindern. Das funktioniere nicht, „wenn wir als ein Land mit einem erheblichen Energiebedarf - pro Kopf liegt er weit über dem Weltdurchschnitt - so tun, als könnten uns die anderen egal sein und als müssten wir hauptsächlich schneller als die anderen Länder sein“ (GRÜNE 02.07.2009: 25689). „Es kann nicht sein, dass die entwickelten Länder immer noch über 50 oder 60 Prozent des Gases und Öles für 15 Prozent der Weltbevölkerung beanspruchen“ (GRÜNE 02.07.2009: 25689). Die LINKE kritisiert die deutsche Energiepolitik als interessengeleitet. So sei die „deutsche Energieaußenpolitik [...] damals von SPD und Grünen militarisiert worden“ (LINKE 02.07.2009: 25694). „Die Bundesregierung betreibt Aufrüstung, weil sie fossile Energiequellen und die Transportwege sichern will“" (LINKE 02.07.2009: 25694). Auf den Klimawandel und die Ressourcenverknappung reagiere die NATO mit atomarer Aufrüstung. Dabei blieben „Frieden, Menschenrechte und eine sichere und nachhaltige Versorgung mit Energie“ „auf der Strecke“ (LINKE 02.07.2009: 25694). Die LINKE plädiert dafür, ,energietechnologisches Wissen mit den Ländern des Südens, zum Beispiel den Ländern Afrikas, vorbehaltlos“ zu teilen und erneuerbare Energien zum „Bestandteil einer Friedens- und Entwicklungspolitik“ zu machen (LINKE 02.07.2009: 25695).

Die Artikulation einer deutschen, Vorreiterrolle ' beim Klimaschutz und den erneuerbaren Energien hat sich etabliert und wird auch im Koalitionsvertrag als gegeben vorausgesetzt: „Unser Ziel ist es [...] Deutschlands Vorreiterrolle beim Klimaschutz beizubehalten“ (Koalitionsvertrag 2009: 26). Man wolle „die Technologieführerschaft bei den Erneuerbaren Energien ausbauen“ (Koalitionsvertrag 2009: 27). Mit seinem Energiekonzept setze Deutschland „für den Ausbau der erneuerbaren Energien und die Reduzierung von $\mathrm{CO}_{2}$ die im weltweiten Vergleich für ein Industrieland ehrgeizigsten Zielvorgaben“ (17/3050: 1). Auch in den Redebeiträgen zum gleichzeitig mit der Laufzeitverlängerung verabschiedeten Energiekonzept wird eine deutsche Vorreiterrolle artikuliert: „Wir sind dort weltweit an der Spitze und einzigartig“ (CDU 28.10.2010: 7168). Das Energiekonzept soll ein „Leitkonzept“ sein, das „Nachahmer in Europa und weltweit“ findet (FDP 28.10.2010: 7174). Es sei das „größte Modernisierungsprogramm für eine gesamte Volkswirtschaft“, „weltweit ein Prototyp“ (FDP 28.10.2010: 7201). Im Zusammenhang mit der Laufzeitverlängerung soll „die effizienteste, die klimaverträglichste und die wettbewerbsfähigste Energieversorgung [...], die es weltweit in einem Industrieland gibt", verwirklicht werden (CDU 28.10.2010: 7178).

Vor „Fukushima“" wird so die Laufzeitverlängerung mit einer international vorbildhaften, klimaverträglichen und wettbewerbsfähigen Energieversorgung unter dem Ziel des Umstiegs auf erneuerbare Energien äquivalenziert. Das Ereignis „Fukushima“ kann in dieser diskursiven Struktur aber nicht verarbeitet werden - die Kernenergie konterkariert die internationale Vorbildfunktion. Die Artikulation einer starken Rolle Deutschlands dient nun dazu, die Kurskorrektur weg von der Kernenergie zu rechtfertigen, „Fukushima“ diskursiv einzubinden und seine dislozierende Wirkung zu überwinden. Wurde vor „Fukushima“ bezweifelt, dass ein vollständiger Umstieg auf erneuerbare Energien auf absehbare Zeit ohne Kernenergie gelingen könne 
wird dies nun unter Zuhilfenahme nationaler Narrative und Mythen sowie der Berufung auf ein nationales Gemeinschaftsgefühls revidiert. Die deutsche Vorreiterrolle, die zuvor bereits mit Klimaschutz und erneuerbaren Energien äquivalenziert wurde, wird nun im Diskurs über die „Energiewende“ zu einem entscheidenden Moment, um ihre Machbarkeit zu vermitteln:

„Welches Land, wenn nicht unser Land, sollte dazu die Kraft haben? Deutschland hat schon so manches Mal gezeigt, was es kann, was in ihm steckt, und hat schon ganz andere Herausforderungen bewältigt [...]. Deshalb sind wir überzeugt: Deutschland hat das Potenzial und die Kraft für eine neue Architektur unserer Energieversorgung [...]. Wir können als erstes Industrieland der Welt die Wende zum Zukunftsstrom schaffen. Wir sind das Land, das für neue Technik, Pioniergeist und höchste Ingenieurkunst ${ }^{66}$ steht. Wir sind das Land der Ideen, das Zukunftsvisionen mit Ernsthaftigkeit, Genauigkeit und Verantwortung für zukünftige Generationen Wirklichkeit werden lässt [...]“( Angela Merkel 09.06.2011: 12963f.).

„[...E]s ist erstmalig und deshalb bislang einmalig, dass sich ein großes Industrieland bereit erklärt, eine solche technologisch-wirtschaftliche Revolution durchzuführen“ (CDU 30.06.2011: 13370). Auch „im Ausland“ erkenne man: „Wenn es ein Land schaffen kann, dann ist es Deutschland“ (CDU 30.06.2011: 13370). Die „Energiewende“ sei ein „Leitprojekt für den Klimaschutz in Europa. Andere Länder schauen auf uns, um zu sehen, wie wir es in unserem hochindustrialisierten Land schaffen, dieses große Projekt ohne Wohlfahrtsverluste zu stemmen“ (FDP 13.06.2013: 31292). Auch SPD und GRÜNE artikulieren eine deutsche Vorreiterrolle, bzw. das Bild einer starken Nation, die die „Energiewende“ ermögliche (z.B.: SPD 30.06. 2011: 13372). Deutschland sei nicht nur Vorreiter bei der „Energiewende“, sondern stehe auch ,an der Schwelle, im 21. Jahrhundert Vorreiter für die Green Economy zu sein“ (GRÜNE 30.06.2011: 13382).

Durch die Konstitution einer nationalen Gemeinschaft als handelndes Subjekt, wird der zuvor bestehende Konflikt über die „Energiewende“ zu verdecken versucht: „Die Deutschen machen sich ans Werk. Es wird gut für unser Land sein, weil wir alle zusammenstehen“ (CDU 30.06.2011: 13371). Die „Energiewende“ wird zum „nationale[n] Gemeinschaftswerk“ (CDU 30.06.2011: 13368) - häufig werden die Worte „wir“" und „unser“ verwendet. Dabei wird explizit auch die Opposition in dieses „Wir“ integriert. Damit verbunden wird aber auch ein konsensualer Anspruch, die Opposition solle ,jetzt endgültig über Ihren Schatten springen“ und „,begreifen, dass jetzt dieses nationale Werk in Deutschland losgeht" (CDU 30.06.2011: 13368). Aber auch SPD und GRÜNE appellieren im Zusammenhang mit einer deutschen Vorreiterrolle an ein kollektives ,Wir' und stärken dadurch diese Story-Line: „Jetzt schaut die Welt auf uns [...]. Wir haben die Verantwortung, zu zeigen, dass der Umbau funktioniert" (GRÜNE 30.06.2011: 13381). Die LINKE fordert die Konstruktion ei-

66 Das Element des, deutschen Ingenieurs' spielt für die Vermittlung der Machbarkeit der „Energiewende“ eine besondere Rolle und zeigt sich in mehreren Zitaten: „Das sind die 140000 Ingenieure unseres Landes, die das als ihr Projekt ansehen [...]. Diese Forscher, Ingenieure, Wissenschaftler machen dabei mit. Das macht unser Land stark“ (CDU 30.06. 2011: 13369). 
nes vermeintlichen Konsenses über eine nationale Gemeinschaft als Initiatorin der „Energiewende“ heraus: Der einzige Grund warum der „Atomausstieg“ „zuerst in Deutschland und nicht in Frankreich oder Polen“ gelinge, sei, dass „es in Deutschland eine ungeheuer starke Antiatombewegung gibt, die jetzt einen Erfolg feiert, für den sie jahrzehntelang gekämpft hat"“ (LINKE 09.06.2011: 12969).

Auch im Koalitionsvertrag von CDU, CSU und SPD der 18. Legislaturperiode wird im Zusammenhang mit der „Energiewende“ auf eine vermeintliche deutsche Vorbildfunktion verwiesen (Koalitionsvertrag 2013: 9). Der deutsche Führungsanspruch bezieht sich dabei auch auf die Europäische Union. Es sei notwendig die „Energiewende“ im europäischen Zusammenhang zu denken, „damit Deutschland auch langfristig Motor eines wettbewerbsfähigen Wirtschafts- und Industriestandorts Europa bleibt" (Koalitionsvertrag 2013:42).

Die internationale Vorbildfunktion (,Wir wollten doch beispielhaft sein $[\ldots]^{\text {“ }}$ (SPD 10.04.2014: 2434)) wird in der 18. Legislaturperiode weiter als eine Motivation für die „Energiewende“ artikuliert: „Wir sind mit der Energiewende angetreten, um $\mathrm{zu}$ zeigen [...], dass eine hochentwickelte Volkswirtschaft wie die deutsche es schafft, sich von nuklearer, langfristig aber auch von fossiler Energieversorgung zu befreien, ohne dabei ihren wirtschaftlichen Erfolg zu gefährden“" (SPD 27.06.3014: 3932). Es gehe auch darum „Nachahmer“ zu finden (SPD 01.06.2016: 16979).

\subsubsection{Strominfrastruktur als zentrale Herausforderung der „Energiewende“}

Der Ausbau der Strominfrastruktur im Sinne eines Netzausbaus für erneuerbare Energien wird vor 2007 (BMU 2007: 12) kaum thematisiert. Die große Koalition der 16. Legislaturperiode verabschiedet dann 2009 das Energieleitungsausbaugesetz EnLAG zum beschleunigten Netzausbau und Netzumbau (vgl. auch CDU 02.07. 2009: 25872). Aber erst in der 17. Legislaturperiode wächst die Bedeutung der (Netz-)Infrastruktur für die Bedeutungsgenerierung erneuerbarer Energien im Bundestag (17/3049: 10). Die FDP bezeichnet neben der Bereitstellung von Speichern die Netzentwicklung als „Dreh- und Angelpunkt des gesamten Umbaus“ (FDP 28.10. 2010: 7201).

Trotz dieser späten Entwicklung spielt diese Story-Line im „Energiewende“Diskurs der 17. und 18. Legislaturperiode eine zentrale Rolle, denn das zu langsame Voranschreiten des Netzausbaus wird zunehmend als zentrales Hindernis für den Umbau der Energieversorgung konstituiert. Die Regierungskoalition verknüpft dies aber nicht in erster Linie mit einer eigenen politischen Verantwortung, sondern weist auf ambivalente Weise die Verantwortung den Befürworter*innen einer „Energiewende“ zu: Verantwortlich seien auch „diejenigen, die im Plenum und in den Ausschüssen die erneuerbaren Energien und deren Ausbau vollmundig befürworten“, aber wenn es um den Netzausbau gehe ,als Erste gegen diese Infrastrukturprojekte wären und den Protest vor Ort organisieren würden“ (CDU 28.10.2010: 7168).

Auch in der 18. Legislaturperiode wird dem Netzausbau eine hohe Relevanz beigemessen. Neben der Problematisierung der Speicherung erneuerbarer Energie (Koalitionsvertrag 2013: 41), wird zunehmend der Knotenpunkt ,Digitalisierung ' mit „Energiewende“ verknüpft, ohne dies jedoch mit konkreten politischen Inhalten zu 
verbinden: „Die anstehende nächste Phase der Digitalisierung betrifft in besonderem Maße die Infrastrukturen: Erfolgsfaktor der Energiewende ist die Digitalisierung der Energieversorgung“ (Koalitionsvertrag 2013: 97).

Der Netzausbau wird im Zusammenhang mit mangelnder Akzeptanz artikuliert, wodurch die Regierungskoalition die politische Verantwortung in ein Außen verschiebt: „Aufgrund der hohen Dringlichkeit des Netzausbaus für das Gelingen der Energiewende ist eine breite Akzeptanz der Bevölkerung notwendig, die heute noch in vielen Fällen nicht gegeben ist" (Koalitionsvertrag 2013: 42). Die fehlende Akzeptanz wird als zentrales Problem bei der Umsetzung der „Energiewende“ konstituiert: „Es gibt einen enormen Aufwand bei der Netzausbauplanung im Einklang mit den Bürgerinnen und Bürgern“ (SPD 01.06.2016: 16987). Es seien „gerade einmal 9 Prozent der Leitungen [...] fertiggestellt“ (CDU 01.06.2016: 16984).

Nachdem die Verantwortung für einen zu langsamen Netzausbau diskursiv in ein Außen verschoben wurde, wird dieser im nächsten Schritt als ein Moment konstituiert, das es notwendig mache, den Ausbau der erneuerbaren Energien ebenfalls zu verlangsamen: „Nur dann, wenn die Netze vorhanden sind, darf der Ausbau der erneuerbaren Energien in dem Maße weiter betrieben werden" (CDU 01.06.2016: 16976). Weil der der Ausbau der erneuerbaren Energien zu schnell voranschreite, passen die „Netzausbauzahlen und die Ausbauzahlen bei den erneuerbaren Energien [...] nicht mehr zueinander“ (CDU 01.06.2016: 16984). Es sei eine „Synchronisierung" erforderlich (CDU 01.06.2016: 16979). Durch diese fehlende Synchronisierung komme es zu „Netzengpässen“ und erneuerbare Energien müssten abgeregelt werden - gleichzeitig können Kohle- und Gaskraftwerke wegen der fehlenden Netzstabilität nicht abgeschaltet werden (SPD 01.06.2016: 16981f.). Der fehlende Netzausbau wird als ein zentrales Hindernis der „Energiewende“ konstruiert: „Die Erneuerbaren [...] helfen uns aber überhaupt nicht, wenn der Netzausbau nur schleppend vorangeht, wenn der Strom also nicht dorthin gebracht wird, wo er gebraucht wird“ (CDU 01.06.2016: 16988). Hier zeigt sich wie über eine Story-Line, die den Netzausbau als zentrale Herausforderung der „Energiewende“ konstituiert und gleichzeitig die Verantwortung in ein Außen verweist, politische Praktiken gerechtfertigt werden, die den Ausbau erneuerbarer Energien verlangsamen.

\section{Versus konventionelle Stromproduktion erfordert überdimensionierten Netzausbau}

Vor allem die LINKEN stellen die Zentralität des Netzausbaus für die „Energiewende“ in Frage und verweist damit auf Brüche in den Artikulationen der Regierungskoalition. Die LINKE argumentiert, der ,überdimensionierte[...] Netzausbau“ sei nur notwendig, weil die Bundesregierung sich nicht von „100 Prozent konventioneller Erzeugung trennen“" wolle (LINKE 01.06.2016: 16985). ${ }^{67} \mathrm{Die}$ LINKE lehnt „,den massiven Ausbau der Übertragungsnetze und der Gleichspan-

67 Nach dieser Argumentation ist der Netzausbau nur notwendig, weil durch die konventionellen Energieträger zu viel Strom im Netz sei. Stattdessen müssten mehr Kohlekraftwerke abgeschaltet werden und statt Offshore-Windenergie vermehrt dezentrale Technologien eingesetzt werden. 
nungsleitungen“ ab. Die hohen Kosten dieses Ausbaus (30 Milliarden) seien „eine Umverteilung des Geldes von Verbraucherinnen und Verbrauchern hin zu den Aktionären" der Übertragungsnetzbetreiber. Sie fordert stattdessen den Kohlestrom zu reduzieren und vermehrt Speicher und Biomasse einzusetzen (LINKE 01.06. 2016: 16986).

\subsubsection{Rolle der Bürger*innen im Kontext von Akzeptanz und Konsens}

Die Rolle der Bürger*innen wird im Kontext von „Energiewende“ bzw. erneuerbare Energien wird zwischen der 14. und 16. Legislaturperiode selten artikuliert. Im Bedeutungszusammenhang mit ,dezentral' werden die Bürger*innen als Investor*innen beschrieben: „Dieses Gesetz wird nicht ohne die Bürger umgesetzt werden können. Es handelt sich um dezentrale Anlagen, die dezentrale Investoren brauchen“ (SPD 25.02.2000: 8437). Die Einführung erneuerbarer Energie entspreche zudem dem Willen der Bürger*innen: „80 bis 90 Prozent der Bürger sagen dort, dass sie sich erneuerbare Energien wie die Solarenergie und die Geothermie wünschen; sie wünschen sich nicht Kernenergie und Kohle, sondern den Umstieg auf erneuerbare Energien“ (GRÜNE 25.02.2000: 8442).

In der 17. Legislaturperiode wird die Rolle der Bürger*innen als Element in Verbindung mit einem Umstieg der Energieversorgung dann häufiger artikuliert. Im Energiekonzept 2010 wird zum Beispiel der „Akzeptanz“ ein hoher Stellenwert beigemessen (17/3049: 18), wobei den Bürger*innen eher eine passive Rolle zugewiesen wird. „Der Umbau zu einer nachhaltigen Energieversorgung“ könne „nur gelingen, wenn die künftige Energiepolitik für die Bürgerinnen und Bürger verständlich und nachvollziehbar ist" (17/3049: 18).

Gleichzeitig mit der Laufzeitverlängerung der Atomkraftwerke zeigt sich hier der Versuch einen energiepolitischen Konsens zu konstruieren und diesen mit der Forderung nach ,Akzeptanz' zu verbinden. So wolle die Bundesregierung ,mit den Wirtschafts- und Umweltverbänden und mit allen interessierten gesellschaftlichen Gruppen nach Wegen suchen, wie der energiepolitische Konsens über die zukünftige Energiepolitik verbreitert werden kann“" (17/3049: 18).

\section{Versus Spaltung statt Konsens durch Laufzeitverlängerung}

GRÜNE, LINKE (LINKE 28.10.2010: 7175) und SPD heben hervor, dass der vermeintliche energiepolitische Konsens ein konstruierter sei, und dass die Einbindung von Bürger*innen von der Regierungskoalition nicht ernst gemeint sei: „die Laufzeiten verlängern und dann einen Pakt ${ }^{68}$ machen! Die Bürger sind doch nicht blöd!“ (GRÜNE 28.10.2010: 7173). „Hunderttausende von Menschen“ würden gegen die Laufzeitverlängerung demonstrieren, was die Regierung nicht inte-

68 Gemeint ist hier der Vorschlag der FDP in der Debatte um die Laufzeitverlängerung mit den Bürger*innen „,einen nationalen Pakt für neue Netze“ (FDP 28.10.2010: 7173) einzugehen. 
ressiere. „Sie spalten die Gesellschaft, obwohl sie sich in diesem Punkt schon einig war“ (SPD 28.10.2010: 7170). Die Oppositionsfraktionen unter GRÜNE, LINKE und SPD zeigen so auf, wie die Bürger*innen in der Entscheidung zur Laufzeitverlängerung einerseits in ein energiepolitisches Außen gedrängt werden, ihre Artikulationen in der Entscheidung zur Laufzeitverlängerung also nicht berücksichtigt werden, während sie gleichzeitig artikulatorisch in einen scheinbaren Konsens eingebunden werden.

Nach „Fukushima“ verstärken sich die Versuche der Regierungskoalition, die Bürger*innen artikulatorisch in den vermeintlichen energiepolitischen Konsens zu integrieren. Insgesamt wird nach „Fukushima“ der Möglichkeitsraum, der sich für marginalisierte Positionen im Falle von Dislokationen (wie hier „Fukushima“) für eine Reartikulation öffnet, sichtbar: Die Position der Regierungskoalition für die Laufzeitverlängerung wird mit ihrem ,Anderen“ konfrontiert (der von sozialen Bewegungen stets benannten Gefahr eines atomaren Unfalls) und kann dies nicht länger verdecken. ${ }^{69}$ Um die Dislokation zu überwinden, müssen Zugeständnisse gemacht werden. Bereits unmittelbar nach „Fukushima“ betont Angela Merkel, dass ihr die „breite Unterstützung und Akzeptanz in der Gesellschaft“ „besonders wichtig“ sei (Angela Merkel 17.03.2011: 10887). Sie verspricht, ,natürlich auch gesellschaftliche Gruppen“ einzubeziehen: „Wirtschaft, Gewerkschaften, Umweltverbände, Kirchen“ (Angela Merkel 17.03.2011: 10886). Durch die diskursive Integration der Bürger*innen in ein kollektives ,Wir' sollen die Differenzen über die „Energiewende“ verdeckt und durch die Anrufung einer gemeinsamen Identität überlagert werden: „Wir alle, Regierung und Opposition, Bund, Länder und Kommunen, die Gesellschaft als Ganzes, jeder Einzelne, wir alle gemeinsam können, wenn wir es richtig anpacken, bei diesem Zukunftsprojekt ethische Verantwortung mit wirtschaftlichem Erfolg verbinden“ (Angela Merkel 09.06.2011: 12964). Als konstitutives Außen dienen dabei alle, die aus dem hegemonial artikulierten Konsens - verbunden mit der durch die Regierungskoalition festgelegten „Energiewende“ - ausbrechen. So mahnt die Bundeskanzlerin den „Kreislauf - hier dagegen und dort dagegen“ zu durchbrechen - es könne nicht sein, dass man einerseits einen schnellen Ausstieg aus der Kernenergie fordere und ,auf der anderen Seite aber eine Protestaktion nach der anderen gegen den Netzausbau“ starte (Angela Merkel 09.06.2011: 12961). Die Artikulation eines kollektiven ,Wir", von dem die Bürger*innen genauso Teil sind wie die Bundesregierung, verdeckt gleichzeitig die Rolle der Bürger*innen für die Entscheidung zur „Energiewende“. Gleichzeitig wird von der Regierungskoalition versucht, das dislozierende Ereignis von „Fukushima“ derart zu überwinden, dass ehemals kritisch positionierte Forderungen in die eigene Äquivalenzkette integriert werden - wie in Kapitel 5.1.3 beschrieben, kommt es zu einer Ausbreitung der hegemonialen Formation. So zeigt sich die CDU in der Debatte über den erneuten Atomausstieg nach „Fukushima“ „überzeugt, dass die Menschen in diesem Lande bei diesem Projekt der Energiewende und der neuen Energiepolitik voll dabei sind. Es ist zuallererst ein

69 Es wird dabei auch deutlich wie die Bürger*innen den Diskurs im Bundestag mit beeinflussen. 
Bürgerprojekt, das heute in Gang gesetzt wird ([...] Ulrich Kelber [SPD]: Das haben die Bürger gegen Sie durchgesetzt!)“, ,,alle Streitigkeiten [...] in den Grundfragen“ seien damit beseitigt (CDU 30.06.2011: 13369).

\section{Versus „Energiewende“ als Erfolg der Bürger*innen}

SPD, GRÜNE und LINKE verweisen auf die Differenz zwischen der Politik der schwarz-gelben Koalition und den für eine „Energiewende“ aktiven Bürger*innen. Sie kritisieren deren artikulatorische Vereinnahmung durch die schwarz-gelbe Koalition: „Die Wahrheit ist: Die Bürgerinnen und Bürger haben dies gegen Sie und Ihre Regierungskoalition durchgesetzt“ (SPD 30.06.2011: 13371). „Dies ist ein Erfolg der Anti-AKW-Bewegung und der Umweltverbände [...]. Frau Bundeskanzlerin, wenn Sie sich bei denen schon nicht entschuldigen wollen [...], so finde ich, dass Sie sich heute bei diesen Menschen für die Nachhilfe hätten bedanken sollen, die sie Ihnen erteilt haben“ (GRÜNE 09.06.2011: 12974). Die GRÜNEN heben hervor, dass diese Bewegungen stets in einem Gegensatz zur Regierungspolitik standen: „Ich bin heute stolz darauf - und auch ein bisschen gerührt -, was eine Bewegung, die früher diskriminiert und kriminalisiert wurde, alles geschafft hat" (GRÜNE 30.06.2011: 13382). ${ }^{70}$

In der 18. Legislaturperiode ebben die Bedeutungskämpfe, die sich nach „Fukushima“ insbesondere in Bezug auf die Anti-Atom-Bewegung, die „Energiewende“ und den Atomausstieg ergaben, allmählich ab. Die Artikulation der Rolle der Bürger*innen reduziert sich nun meist auf den Kontext von Akzeptanz und Konfliktvermeidung. So sollen die Bürger*innen in die „Energiewende“ eingebunden werden, damit sie zukünftig Proteste unterlassen: „Der eigene Hund macht keinen Lärm - er bellt nur“ (CDU 01.06.2016: 16991). Dies gilt insbesondere beim Netzausbau: „Für den Ausbau der Stromnetze muss bei den betroffenen Anliegern um Akzeptanz geworben werden“ (Koalitionsvertrag 2013: 42). Zudem werde ein „Kompetenzzentrum Naturschutz und Energiewende ${ }^{71 ، ~}$ eingerichtet, das der Konfliktvermeidung diene und Debatten versachlichen solle (Koalitionsvertrag 2013: 44). Die Verabschiedung eines Gesetzes zur Förderung von Mieterstrom gegen Ende der Legislaturperiode solle ebenfalls der Akzeptanz der „Energiewende“ dienen: „Bei der Energiewende ist aber auch Akzeptanz wichtig [...]. Nicht nur Hauseigentümer sollten davon profitieren, sondern wir als Sozialdemokraten meinen, dass auch Mieterinnen und Mieter vergleichbare Möglichkeiten haben müssen, diese Energiewende zu nutzen“ (SPD 29.06.2017: 24987).

Insgesamt zeigt sich nach „Fukushima“ besonders anschaulich, wie die Bürger*innen als Subjekte im Diskurs einerseits Einfluss auf den Diskurs im Bundestag üben (können) $)^{72}$ und andererseits darauf folgende (bundes)politische Praktiken wie-

70 Auch die GRÜNEN artikulieren gleichzeitig eine Einheit zwischen ihrer Politik und der Bürger*innenbewegungen, indem sie sich in diese mit einbeziehen (,Wir alle - ich habe es am Anfang gesagt - haben unser Land verändert“ [GRÜNE 30.06.2011: 13382]).

71 www.naturschutz-energiewende.de

72 Es sei hier auf die großen Demonstrationen nach „Fukushima“ verwiesen. 
derum direkten Einfluss auf ihre Lebenswelt üben, Bürger*innen also - wenn auch möglicherweise marginalisierter - Teil des Bundestags-Diskurses sind. Die Konstitution der Rolle der Bürger*innen im Kontext von Akzeptanz und die damit verbundenen Externalisierungsprozesse werden in Kapitel 6.4 nochmals aufgegriffen.

\section{Versus Bedrohung der Bürger*innenenergie durch EEG-Novellierungen}

GRÜNE und LINKE heben dagegen immer wieder eine aktive Rolle der Bürger*innen für die „Energiewende“ hervor und arbeiten heraus, wie diese aktive Rolle durch die politische Praktiken im Bundestag immer wieder marginalisiert werde. Insbesondere werden hier die Novellierungen des EEG 2014 und 2016/17 genannt: Die Regierung wolle „das weitere Engagement und Investitionen dieser Akteure abwürgen“, indem sei kleine Bürger*innenenergieprojekte unter $18 \mathrm{MW}$ nicht von der Ausschreibungspflicht befreie (GRÜNE 01.06.2016: 16974). ${ }^{73}$ Das Motto der schwarz-roten Regierung sei: „Nehmt es den Bürgern, gebt es den Konzernen“ (GRÜNE 29.06.2017: 24991). Sie mache eine Politik gegen die Mehrheit, die wolle, „dass die erneuerbaren Energien noch stärker ausgebaut werden“ und der Kohleausstieg beschlossen werde (GRÜNE 01.06.2016: 16975).

Auch die LINKE kritisiert, die große Koalition blockiere mit ihrem Ausschreibungsmodell im EEG die Bürgerenergie und ,schanz[e] das Geschäft mit Erneuerbaren-Strom internationalen Fonds und Konzernen zu“ (LINKE 01.06.2016: 16985). Das gefährde „massiv eine [...] dezentrale Stromerzeugung“ (LINKE 27.06.2014 3934f.). Gegen Ende der Legislaturperiode kritisiert die LINKE die Regierungskoalition habe „die erneuerbaren Energien zu einem Spiel- und Experimentierfeld für Spekulanten gemacht“ (LINKE 29.06.2017: 24988), was im Gegensatz zu einer von Bürger*innen gestalteten „Energiewende“ stehe. Zwar zeige sich bei den Ausschreibungen „eine hohe Beteiligung von sogenannten Bürgerenergiegesellschaften“. Dabei handele es sich aber vermutlich nur noch um ,windige Konstruktionen von Rechtsanwaltsbüros der großen Projektierer“ (LINKE 29.06.2017: 24988). ${ }^{74}$

73 Die GRÜNEN berufen sich dabei auf die Empfehlungen der EU-Wettbewerbskommissarin Windenergieanlagen bis maximal $18 \mathrm{MW}$ von der Ausschreibungspflicht zu befreien. Stattdessen sind nur Wind- und Solarenergieanlagen bis zu einer De-minimis Grenze von 750kwp von der Ausschreibungspflicht befreit. Solaranlagen unter dieser Grenze können weiterhin eine feste Einspeisevergütung in Anspruch nehmen.

74 Bürgerenergiegesellschaften werden im EEG 2016/2017 Sonderregelungen gewährt. Diese Sonderregelungen werden von anderen Gesellschaften genutzt, indem sie sich der Definition von Bürgerenergieprojekten im EEG (z.B. mindestens 10 Privatpersonen als Anteilseigner*innen) anpassen. Ein solcher „Missbrauch“ wird auch von der Bundesnetzagentur bestätigt: „Der überwiegende Teil der Bürgerenergiezuschläge geht an Gesellschaften, aus deren Geboten ersichtlich wird, dass sie zumindest organisatorisch einem einzelnen Projektierer zuzuordnen sind“ (www.bundesnetzagentur.de). 


\subsubsection{Wissenschaft als Schlüssel zum Gelingen der „Energiewende“}

Der Stellenwert von externem Wissen erhöht sich nach „Fukushima“ deutlich, sodass auch die Rolle der Wissenschaft für eine gelungene „Energiewende“ als Story-Line in den Fokus rückt. Wobei zunächst die Äquivalenzierung mit dem Knotenpunkt ,Wissenschaft‘ in Bezug auf die Entscheidung der schwarz-gelben Regierung zur Verlängerung der Laufzeiten zur Entpolitisierung dieses gesetzgeberischen Vorgangs beitragen soll (z.B. FDP 17.03.2011: 10895). So ei ein technisches Versagen unerwartbar gewesen, da der Betrieb von Kernkraftwerken auf wissenschaftlichen Grundlagen erfolge: „Die unfassbaren Ereignisse in Japan lehren uns, dass etwas, was nach allen wissenschaftlichen Maßstäben für unmöglich gehalten wurde, doch möglich werden konnte [...]“" (Angela Merkel 17.03.2011: 10884). Bei der ,Neubewertung“ der Atomenergie wird dann der Wissenschaft eine herausragende Rolle zugewiesen, die sich in der Einbeziehung der externen Kommission, „Ethikkommission Sichere Energieversorgung“, materialisiert. Die Kommission stellt in ihrem Bericht unter dem Titel „Deutschlands Energiewende - ein Gemeinschaftswerk für die Zukunft“ Atomausstieg und „Energiewende“ in ein äquivalentes Verhältnis und schlägt gleichzeitig gesetzgeberische Maßnahmen vor. Dieser Bericht spielt in den Bundestagsdebatten nach „Fukushima“ eine wichtige Rolle und wird als Teil des Diskurses um „Energiewende“ betrachtet. Erst nach Vorlage des Berichtes der Kommission beschließt der Bundestag den schrittweisen Ausstieg aus der Atomenergie. Die Arbeit der Kommission spielt somit für die Legitimation der politischen Entscheidung zum „Atomausstieg“ und zur „Energiewende“ eine große Rolle:

„Dass es bei diesem kontrovers diskutierten Thema gelungen ist, den Sachverstand von Wissenschaft, Wirtschaft und Technik und den Sachverstand der breiten Gesellschaft und der Politik zu bündeln und in konkretes politisches Handeln umzusetzen, ist eine großartige Leistung der Bundeskanzlerin und dieser Bundesregierung“" (CSU 09.06.2011: 12971).

Die wissenschaftliche Begleitung, nicht nur der politischen Prozesse bei der „Energiewende“ unmittelbar nach „Fukushima“, erhält in den nachfolgenden Debatten einen höheren Stellenwert. ${ }^{75}$ Es solle ein jährliches „Monitoring“ zur „Energiewende“ eingeführt werden, das die Zielerreichung kontrolliere, und das von einer unabhängigen Expert*innenkommission begleitet werde. Die Notwendigkeit eines Monitorings wird mit der hohen Komplexität der „Energiewende“ begründet und wird als Bestandteil der Regierungserklärung zum Atomausstieg nach „Fukushima“ artikuliert: „Es ist ja wahr: Es scheint einer Quadratur des Kreises nahezukommen, all das schaffen zu wollen, was wir uns vorgenommen haben. Deshalb ist ein fünfter Punkt zwingend und unerlässlich: die Einrichtung eines lückenlosen Monitoringprozesses“ (Angela Merkel 09.06.2011: 12963). Über den „Fortschrittsbericht“ und das „Monitoring“ sollen Probleme bei der „Energiewende“ lösbar werden: „Deshalb wollen wir

75 Krick (2018) untersucht die Rolle der hohen Anzahl an Expert*innenkommissionen in der Deutschen Energiewende-Politik, die sie im Rahmen von ,Konsens-Management‘ der Bundesregierung klassifiziert. 
diesen jährlichen Fortschrittsbericht. Wir wollen ihn, um dann nachjustieren zu können, und zwar nicht beim Enddatum des Ausstiegs, sondern bei dem, was auf diesem Weg noch notwendig ist und wo blockiert wird“ (CSU 09.06.2011: 12973).

Dabei wird der Energieforschung eine besondere Rolle zugewiesen: „Energieforschung ist der Schlüssel zum Gelingen der Energiewende“ (CDU 13.06.2013: 31546). Die Technologieorientierung im Rahmen der Story-Line ,Wissenschaft als Schlüssel zum Gelingen der „Energiewende““ wird dabei in eine übergeordnete Erzählung von ,Wachstum und Wohlstand“ eingeordnet: „Zukunftstechnologien sind für uns ein wesentlicher Bestandteil der Energiewende. Wir haben die Energieforschung zum zentralen Baustein unserer Technologiestrategie und damit zum Garanten für Wachstum und Wohlstand gemacht" (CDU 13.06.2013: 31547). Demnach überrascht es nicht, dass die Story-Line über die Rolle von Wissenschaft und Forschung eine zunehmend verwertungsorientierte Ausrichtung erhält, die sich im Diskurs auch während der 18. Legislaturperiode weiter festigt. So solle die Energieforschung „konsequent auf die Energiewende ausgerichtet“ werden, wobei „Forschungsergebnisse [...] zügig in Form von innovativen und marktfähigen Produkten verwertet werden“ müssen (Koalitionsvertrag 2013: 25f.). Dabei liege der Fokus auf „,intelligente[n] Lösungen insbesondere in den Bereichen Energieeffizienz, Energieeinsparung, Erneuerbare Energien und Versorgungssysteme“ (Koalitionsvertrag 2013: 25) und weniger auf sozialen und ökologischen oder Querschnittsbereichen. Dies sei auch für den „exportorientierten Technologiestandort[...] Deutschland“ von Bedeutung“ (Koalitionsvertrag 2013: 26). Hier zeigt sich auch die mitunter enge Verknüpfung mit der Story-Line ,Deutschland als Vorreiter'. Die Rolle von Wissen und Technologie für die Erzählung von Nation betrachte ich in Kapitel 6.4 genauer.

Was die Überprüfung politischer Maßnahmen durch externe Expert*innenkommissionen betrifft, so spielen diese auch in der 18. Legislaturperiode weiterhin eine Rolle für die Legitimation politischer Entscheidungen. So solle zum Beispiel ein „Nationaler Aktionsplan Energieeffizienz“ von einer „unabhängigen Expertenkommission“ in „einem jährlichen Monitoring“ überprüft werden (Koalitionsvertrag 2013: 37). Die Ergebnisse dieser Kommissionen werden allerdings in den Debatten selten aufgegriffen (z.B.: GRÜNE 10.04.2014: 2449).

\section{Versus Verlagerung politischer Verantwortung und Verengung der Energieforschung}

Aus der Opposition wird vor allem in der 17. Legislaturperiode im Zuge der Einsetzung der Ethikkommission eine Verschiebung politischer Verantwortung aus wahltaktischen Gründen kritisiert und somit die Ambivalenzen in der Anrufung von Wissenschaft hervorgehoben: „Deutschland braucht keine Regierung, die [...] Kommissionen einberuft, nur um über Landtagswahlen hinwegzukommen [...]. Deutschland braucht ein selbstbewusstes Parlament, das seine Aufgabe wahrnimmt“ (SPD 24.03.2011: 11301). Die LINKE verweist zudem auf einen Widerspruch zwischen wissenschaftlicher Expertise und Regierungspolitik. So würden wissenschaftliche Ressourcen, z.B. beim Umweltbundesamt durch die „dauernden Angriffe [...] gegen das Erneuerbare-Energien-Gesetz“ vor allem der FDP gebunden und „,verschleudert“. Die Ressourcen wären vielmehr nötig gewesen, um den Umbau des Energieversorgungssystems zu planen (LINKE 13.06.2013: 31294). 
Darüber hinaus wird eine Verengung des Energieforschungsprogramms kritisiert: Die „Tragweite und Komplexität der Energiewende“ spiegele sich nicht im Energieforschungsprogramm der Bundesregierung wider (SPD 13.06.2013: 31584). Die GRÜNEN weisen darauf hin, dass „die interdisziplinäre Forschung zu sozialwissenschaftlichen und technischen Fragen einer Energiewende mit ihren dezentralen Strukturen [...] in der Hochschullandschaft eher ab- als ausgebaut" werde (GRÜNE 13.06.2013: 31550f.). Auch die LINKE fordert eine Ausweitung der Energieforschung über rein ökonomische und technologische Fragen hinaus. Die Politik müsse sich fragen, wie eine Energieforschung aussehen könne, „die die Herausforderung der Energiewende meistert? Es geht also um die Unterstützung für einen Prozess des strukturellen Umbaus unserer Energieversorgung - um eine Transformation und damit auch um Transformationsforschung" (LINKE 13.06.2013: 31549). Dazu gehören auch die „Rahmenbedingungen der Energiewende“, z.B. wie „Nachwuchsförderung und Berufsausbildung [...] auf eine dezentrale Energieversorgung eingestellt werden“ können oder die wissenschaftliche Begleitung der „Rekommunalisierung von Netzen und Erzeugern“. Zudem müsse erforscht werden wie ,diese Transformation ohne soziale Härten, sondern in einem gerechten Verteilungsmodus“" gestaltet werden könne“ (LINKE 13.06.2013: 31550). Die LINKE fordert somit den hegemonialen Diskurs einer marktorientierten und auf ökonomische Verwertbarkeit ausgerichteten „Energiewende“ im Bereich der Forschung heraus und bringt zum ersten Mal ,Transformation“ in die Bedeutungsgenerierung von „Energiewende“ mit ein.

\subsubsection{Die ,großen Vier' als Repräsentanten des herkömmlichen Energiesystems}

In den energiepolitischen Debatten werden die großen vier Energiekonzerne (gemeint sind RWE, E.ON, EnBW und Vattenfall) immer wieder als die ,großen Vier ${ }^{6}$ bezeichnet und erscheinen somit als einzelner Akteur innerhalb des Diskurses. Sie werden häufig mit einer affirmativen Energiepolitik im Gegensatz zu einem Umstieg auf erneuerbare Energien, bzw. zu einer „Energiewende“, assoziiert. Während sich die bisher identifizierten Story-Lines zwischen der 14. und 18. Legislaturperiode über verschiedene politische Spektren entwickeln, wird die hier vorliegende Einordnung der Energiekonzerne überwiegend vom linken politischen Spektrum artikuliert (SPD, GRÜNE, PDS/LINKE) und weist eine eher kritische Positionierung zur hegemonialen Formation auf (die wie bereits mehrfach betont nicht zwingend mit den Fraktionsgrenzen identisch ist).

Bereits in der 15. Legislaturperiode werfen SPD und GRÜNE den sogenannten ,Monopolisten “ - wie die ,großen Vier' ebenfalls bezeichnet werden - vor, die Förderung erneuerbarer Energien als Vorwand für ungerechtfertigte Preiserhöhungen auszunutzen und sie damit zu diskreditieren: „Fakt ist: Die Stromkonzerne haben im letzten Jahr mehr auf die Strompreise umgelegt, als tatsächlich eingespeist wurde. Ursache dafür war der heiße Sommer. Die Stromkonzerne hätten die Strompreise also am Anfang des Jahres mit dem Hinweis auf das EEG senken und nicht erhöhen müssen“ (GRÜNE 09.09.2004: 11247). In der 16. Legislaturperiode zeigt sich der Dissens über die Rolle der Energiekonzerne auch innerhalb der großen Regierungs- 
koalition. Vor allem GRÜNE, LINKE und z.T. SPD verorten sich kritisch gegenüber den innerhalb der hegemonialen Formation verorteten für das herkömmliche Energiesystem stehenden Energiekonzernen, die, von Profitgier getrieben, an der konventionellen Energieerzeugung festhalten, um ihre Monopolstellung zu bewahren, und aus diesem Grund die erneuerbaren Energien torpedieren. So argumentiert die SPD, die „Fotovoltaik“ werde angegriffen, weil „Firmen wie Eon und RWE“ aufgrund der dezentralen Erzeugung damit „kein Geld verdienen können“ (SPD 06.06.2008: 17731). Die GRÜNEN verweisen auf einen Vorwurf der EU-Kommission gegen E.ON, der zeige, dass „der Strommarkt wegen der Dominanz der Energiekonzerne nicht funktionier[e]“: „Eon hat Kraftwerke gedrosselt oder abgeschaltet, um das Stromangebot zu verringern und den Börsenpreis für Strom zum eigenen Nutzen in die Höhe zu treiben ${ }^{76 ، ~(G R U ̈ N E ~ 02.07 .2009: ~ 25877) . ~ I m m e r ~ w i e d e r ~ w i r d ~ d e r ~ V o r-~}$ wurf der direkten Einflussnahme durch die Konzerne auf die Bundespolitik erhoben:

„Wirksame Maßnahmen der EU-Kommission gegen die Energiekonzerne zur Eindämmung der Monopolwirtschaft werden von der Bundesregierung gezielt verhindert. Erst vor kurzem hat sie einen Vorschlag Brüssels zur Zerschlagung des Stromkartells zu Fall gebracht - ganz nach dem Wunsch von Eon, RWE, Vattenfall und EnBW“ (LINKE 02.07.2009: 25876).

Der Dissens über die Rolle der großen Energiekonzerne verstärkt sich im Vorfeld der Bundestagswahl 2009, bei der es um eine „Richtungsentscheidung“ gehe (SPD 02.07.2009: 25880). Ein potenzieller Wahlgewinn von CDU, CSU und FDP wird dabei mit einem Gewinn der großen Energiekonzerne äquivalenziert:

„Wollen wir die eingeleitete Energiewende und das Jobwunder bei den erneuerbaren Energien weiterführen, oder setzen sich die Atomkonzerne RWE, Eon, Vattenfall und EnBW durch und würgen die Energiewende ab, stoppen den Ausbau der erneuerbaren Energien und vernichten dadurch die Arbeitsplätze bei den erneuerbaren Energien, und das nur, weil man mit einem abgeschriebenen Atomkraftwerk jeden Tag 1 Million Euro verdienen kann? Die Wählerinnen und Wähler haben die Wahl zwischen Gemeinwohl und den Interessen der Energiekonzerne.“ (SPD 02.07.2009: 25880)

Die schwarz-gelbe Koalition wird im Zuge des Dissenses über die Laufzeitverlängerung der 17. Legislaturperiode zur Repräsentantin der Energiekonzerne erhoben, die Entscheidungen in deren Profitinteresse treffe: „Sie haben ein paar Lastwagen mit Geld in Bewegung gesetzt [...]. Die Lkw fahren nacheinander vier Adressen ab. Die vier großen Dinosaurier der Energiewirtschaft bekommen, je nachdem, wie sich die Strompreise entwickeln, zwischen 40 und 100 Milliarden Euro zugeschustert“ (SPD 28.10.2010: 7169). „Hinterher können Sie sagen: Wir haben vier Konzerne reich und Millionen Menschen arm gemacht“ (LINKE 28.10.2010: 7176). „Die Macht der Energiekonzerne wird somit noch weiter gestärkt“ (LINKE 28.10.2010: 7196). Das schwäche auch die Stadtwerke und die Investitionen in erneuerbare Energien: „Sie enteignen sie zugunsten von Eon, RWE und Co“ (GRÜNE 28.10.2010: 7178)). Die

76 „Leider hat die EU-Kommission das Verfahren gegen Eon gegen einen Vergleich eingestellt“(GRÜNE 02.07.2009: 25877). 
LINKEN sprechen von „Klientelpolitik“, die „die Gesellschaft spaltet“ und bei der „[v]ier Konzerne [...] gewinnen, und Millionen und Abermillionen Menschen [...] verlieren“ (LINKE 28.10.2010: 7175). Teile der Bundesregierung seien mit Kernkraftlobbyisten eng verbandelt (GRÜNE 24.03.2011: 11293). Der Bundeswirtschaftsminister wird als „Bundesmonopolminister“ bezeichnet (SPD 28.10.2010: 7173).

Es wird zudem mehrfach artikulatorisch auf einen Widerspruch zwischen Absprachen mit Energiekonzernen und demokratischen politischen Entscheidungen abgezielt: „Es bedarf keines mit den Energiekonzernen abgestimmten energiepolitischen Gesamtkonzepts, sondern politischer Entscheidungen. Auf der politischen Ebene entscheidet sich, ob der Energiewechsel, den die Gesellschaft vollzieht, beschleunigt wird“ (SPD 28.10.2010: 7185). Dagegen sei durch das alleinige Aushandeln der Verträge mit den Konzernen die Politik ,entmachtet“" worden (LINKE 28.10.2010: 7175). „Die Atompläne der Bundesregierung gefährden, wie ich versucht habe nachzuweisen, die Demokratie“ (LINKE 28.10.2010: 7176).

Nach „Fukushima“ versucht vor allem die schwarz-gelbe Regierungskoalition die ,großen Vier“ in einen nun neu zu schließenden Konsens über die „Energiewende“ diskursiv zu integrieren und ihnen dabei eine zentrale Rolle zuzuweisen. So begrüßt die CDU den Wandel in der Haltung des Konzerns E.ON, der gegen den Atomausstieg gewesen sei, aber nun die „Energiewende“ zu einer „riesigen Chance“ erkläre und die Energiewirtschaft sich ,an die Spitze“ der Bewegung stelle (CDU 30.06. 2011: 13368f.). Die ,großen Vier' sollen nun nicht mehr für das herkömmliche Energiesystem stehen, sondern als Teil der hegemonialen Formation in die Äquivalenzkette um „Energiewende“ integriert werden. Hier wird deutlich, wie sich durch eine solche Reartikulation politische Praktiken konstituieren, die sich später in entsprechenden Energieerzeugungs- und versorgungsstrukturen materialisieren: So kritisieren die GRÜNEN, die Regierungskoalition wolle durch die Novellierung des EEG und das darin enthaltene Ausschreibungsdesign die Akteursvielfalt bei der „Energiewende“ zu Gunsten der „Energieoligopole“ beschädigen (GRÜNE 01.06.2016: 16974). Auch die LINKEN führen den Paradigmenwechsel im EEG hin zu Ausschreibungen und „Markteinführung“ auf die „Lobbyarbeit“ der großen vier Stromkonzerne zurück, die „um ihre Marktmacht bangen“ (LINKE 27.06.2014: 3940). So werde auch Windkraft auf See nur deshalb so stark gefördert, weil dabei Bürger*innen nicht teilhaben können, sondern große Konzerne und Akteur*innen wie „Goldman Sachs, RWE, Vattenfall, Eon, der Staat Dänemark und Siemens“ verdienen (LINKE 01.06.2016: 16985). „Als Linke werden wir weiter gegen die Marktmacht von RWE, Eon, Vattenfall und EnBW und für eine Stromwirtschaft in Bürgerhand kämpfen“ (LINKE 27.06.2014: 3941). Durch die Integration der ,großen Vier“ in die Äquivalenzkette um „Energiewende“, die nach „Fukushima“ Teil der hegemonialen Formation wird, wird die kritische Positionen, welche die ,großen Vier" als Gegner der „Energiewende“ konstituierte, weiter marginalisiert, da die antagonistische Grenze zwischen Hegemonie und Gegen-Hegemonie verschwimmt ${ }^{77}$, wie in Kapitel 5.1.3 gezeigt wurde.

77 Da die Forderung einer „Energiewende“ nun sowohl Teil des hegemonialen als auch Teil des gegenhegemonialen Diskurses ist, befindet sie sich in einem Spannungsfeld zwischen 


\section{Versus Demokratisierung der Energieversorgung}

Vor allem die LINKE stellt insbesondere nach „Fukushima“ dem Einfluss der vier Energiekonzerne (LINKE 30.06.2011: 13378) die Forderung einer Demokratisierung der Energieversorgung entgegen. Die Macht der vier Konzerne, die „sich die Bundesrepublik Deutschland feudal aufgeteilt haben“ “ (LINKE 24.03.2011: 11285), erfordere eine demokratische Kontrolle durch Preisregulierung: „Wieder geht es um die Frage der Zuständigkeit der Politik und der Demokratie. Sie begreifen eine einfache Tatsache nicht: Der Bundestag wird demokratisch gewählt; die Atomlobby wird nicht gewählt“ (LINKE 24.03.2011: 11285). Die Politik müsse die Kraft entwickeln, den „Konzernlobbyisten“ zu widerstehen „und den Vorrang der demokratischen Institutionen zu sichern“ (LINKE 17.03.2011: 10898). Ein „Energiekonzept der Zukunft“ müsse mit „unabhängigen Wissenschaftlerinnen und Wissenschaftlern, Umweltverbänden und kommunalen Energieversorgern erarbeitet werden“ (LINKE 17.03.2011: 10898). Einigungen dürften nicht mit der „Atomlobby“ ausgehandelt werden, sondern seien demokratisch zu erzielen - das sei auch der Fehler von rot-grün gewesen (LINKE 24.03.2011: 11283). Die Politik, nicht die Konzerne, müssten wieder für die Daseinsvorsorge zuständig sein, das sei eine Frage der Demokratie (LINKE 09.06.2011: 12970). So können Entscheidungen vor Ort demokratisch getroffen werden: „Wenn Sie alles privatisiert haben, hat der Bürgermeister nichts mehr zu entscheiden, weder hinsichtlich der Energiepreise noch hinsichtlich der Wasserpreise oder der Mieten [...]. (Volker Kauder [CDU/CSU]: Wir wollen keine Situation wie in der DDR!)“ (LINKE 24.03.2011: 11284). Daher sollen auch die Stromnetze wieder in öffentliche Hand überführt werden: „Wenn die Stromnetze nicht in öffentlicher Hand sind, dann ist die Politik auch nicht zuständig. Wenn die Politik nicht zuständig ist, dann ist auch die Demokratie nicht zuständig“ (LINKE 24.03.2011: 11284). Die LINKE fordere daher in letzter Konsequenz ,eine Zerlegung“ und „eine Rekommunalisierung“ der vier Konzerne (LINKE 30.06.2011: 13378).

\subsection{FANTASMATISCHE NARRATIVE IM KONTEXT DES DISKURSES UM „ENERGIEWENDE“}

Dieses Kapitel zielt auf die ,großen sinnstiftenden Erzählungen“ hinter den StoryLines, also auf die Kräfte hinter den Bedeutungssystemen, ab. Fantasmatische Narrative spielen eine Rolle bei der Verdeckung der Nicht-Naturgegebenheit sowie der Entpolitisierung sozialer Praktiken. Im Rahmen des in Kapitel 4.2.3 beschriebenen Analyseverfahrens wurden auf Grundlage der als zentral identifizierten Story-Lines drei fanstasmatische Narrative herausgearbeitet, die für die Bedeutungsgenerierung von „Energiewende“ als maßgeblich erachtet werden. Im Folgenden werden diese Narrative dargestellt, mitsamt ihrer glücksverheißenden Dimension, d.h. der kommenden Erfüllung, auf die sie verweisen (Glynos/Howarth 2007: 147f.). Zuvor wer-

Hegemonie und Gegen-Hegemonie und kann nicht mehr als zentrale Forderung für eine ausschließlich kritisch positionierte populare Äquivalenzkette stehen. 